\title{
MODAL PROPERTIES AND SEISMIC BEHAVIOUR OF BUILDINGS EQUIPPED WITH EXTERNAL DISSIPATIVE PINNED ROCKING BRACED FRAMES
}

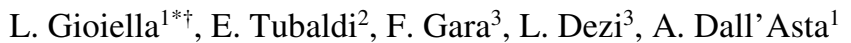 \\ ${ }^{1}$ School of Architecture and Design, University of Camerino, Viale della Rimembranza, 63100 Ascoli Piceno (AP), Italy. \\ ${ }^{2}$ Department of Civil and Environmental Engineering, University of Strathclyde, 75 Montrose Street, Glasgow G1 1XJ, \\ Scotland, UK. \\ ${ }^{3}$ Department of Civil and Building Engineering and Architecture, Polytechnic University of Marche, Via Brecce Bianche \\ Ancona (AN), Italy.
}

\begin{abstract}
SUMMARY
This paper deals with the seismic protection of building frames by means of external dissipative systems. Dampers and external framing system can be arranged in several configurations, involving different kinematic behaviours and seismic performances. This study analyses a recently-developed solution called "dissipative tower", which exploits the rocking motion of a steel braced frame, hinged at the foundation level, for activating the dampers. This system aims at controlling both the global response and the local storey deformation of the frame, by using a reduced number of viscous dampers. A state space formulation of the dynamic problem is presented in general terms, together with the solution of the seismic problem via the modal decomposition method.

A parametric study is carried out to evaluate the influence of the added damping and of the braced frame stiffness on the modal properties and seismic response of a benchmark reinforced concrete frame retrofitted with the external dissipative towers. It is shown that the addition of the towers yields a regularization and reduction of the drift demand along the building height, but it may induce significant changes, not always beneficial, in the distribution of internal actions of the frame and in the absolute storey accelerations.
\end{abstract}

Keywords: Passive Seismic Protection, Viscous Dampers, External Seismic Retrofit, Dissipative Towers, Rocking motion.

\section{INTRODUCTION}

Passive damping systems have proven to be very efficient solutions for the seismic protection of new constructions and retrofitting of existing structures [1]-[4]. Dampers are traditionally installed within a building frame in either diagonal or chevron brace configurations connecting adjacent storeys. This type of damping system, whose effectiveness has been investigated in numerous studies (e.g. [5]-[11]), presents some disadvantages, particularly when employed for retrofitting existing buildings. Usually, the addition of dissipative diagonal in existing frames provides an increment of axial forces in the columns and this may lead to premature local failures, as observed numerically in the case of moment resisting frames equipped with nonlinear hysteretic dampers [12], [13] as well as with linear viscous dampers [14]. In order to avoid this, column strengthening may be required, in the case of existing frames [12], or application of specific capacity design rules, in the case of newly designed moment resisting frames [14]. Furthermore, there may be some feasibility limits on the strengthening of the existing foundations at the base of the bracing system. Also, the indirect costs related to the interruption of the building utilization during the installation of the retrofit system can be very high, particularly for strategic buildings, hospitals or schools.

These problems could be solved efficiently by using external damper configurations, where the dissipative bracings and the relevant foundations are placed outside the construction [15]. External dampers and bracing components can be arranged in very different configurations and the possible solutions can be grouped into three main categories, characterized by substantially different kinematic behaviours, but all permitting the control of both the total amount of the dissipated energy and the frame deformation at the various storeys. In the first arrangement (Fig. 1 a), the dampers are placed horizontally at floor level, between the frame and an external stiff structure [16]-[18]. This way, the links are activated by the relative displacements between the frame and the external structure. A similar configuration can be obtained by placing the dampers between adjacent buildings, though this solution is efficient if the two buildings have strongly different dynamic properties [19]-[22]. An alternative arrangement consists in coupling the frame with an external shear deformable bracing structure (Fig. 1 b). The new and existing structures are connected at the storey level and the dissipative devices, incorporated in diagonal braces within the new structure, are activated by the relative displacements between adjacent floors, as in the more traditional case of dissipative braces placed within the existing structure [3]. A third arrangement, denoted as "dissipative tower" consists in external stiff bracings linked to the frame

\footnotetext{
* Correspondence to: Dr. Laura Gioiella, School of Architecture and Design, University of Camerino, Viale della Rimembranza, 63100 Ascoli Piceno (AP), Italy.

$\dagger$ E-mail: laura.gioiella@unicam.it
} 
at the storey level and connected at the foundations by a hinge (Fig. $1 \mathrm{c}$ ). The energy dissipation is provided by dampers placed at the external frame base and activated by its rocking motion. The high stiffness of the braced frame promotes a uniform distribution of the inter-storey drift of the protected frame. Recently, this system has been employed for the seismic design of new constructions and for retrofitting existing buildings [23], [24] and a patent covering a technological solution was registered [25]. A theoretical study [26], in the field of the stochastic dynamic, has compared the performance of this system with that of the system of Fig. 1 a).

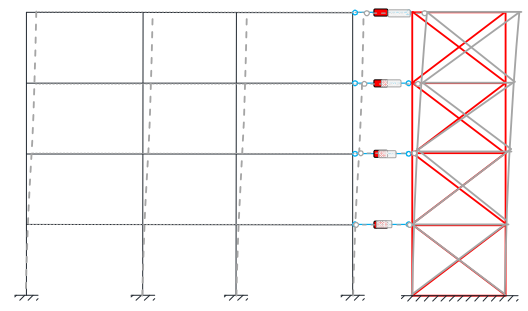

a)

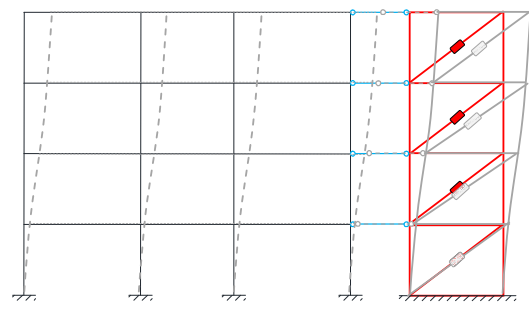

b)

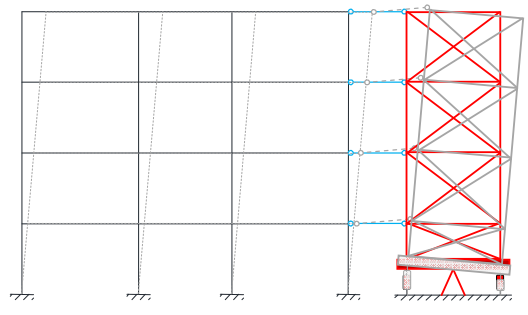

c)

Fig. 1. Illustration of three categories of external dissipative systems: a) dampers placed horizontally at the storey level between the frame and an external stiff contrasting structure; b) dampers incorporated within a new shear deformable structure; c) pinned rocking bracing with dampers located at the base

The rocking motion of structures has emerged in the last few years as an efficient way to reduce seismic damage [27][29], and some studies have also investigated the coupling of existing frames with external rocking structures [30], [31]. It is noteworthy that in the literature the term "rocking" is used to describe various configurations, exhibiting different types of behaviour. In general, it is possible to distinguish between "stepping rocking" and "pinned rocking" [32], [33]. The first type of rocking denotes structures characterized by an alternation of pivot points, capable of recentering thanks to their self-weight, whereas the second denotes structures rotating about a hinge placed at the foundation level. For example, the dissipative tower of Fig. 1, which is considered in this paper, can be classified as a "pinned rocking" configuration enhanced with linear fluid viscous dampers. The work of [27] shows that moment-resisting frame can be effectively protected against near-fault ground motion effects by coupling them with pinned rocking walls rather than with fixed-based walls. In [28], rocking wall-frame structures with supplemental draped tendons enhanced with dampers and fuse elements are proposed for the seismic protection of existing buildings. In [29], the results of dynamic tests performed on precast, post-tensioned rocking walls equipped with external dissipative devices are reported. The external devices, located in parallel to post-tensioned tendons, which guarantee recentering, can be fluid viscous dampers, tension-compression yielding steel dampers or a combination of both of them. In [30], external pin-supported walls are used for the seismic retrofit of an eleven-storey steel reinforced concrete frames. Pinned-walls allow to control the displacements distribution, while the seismic performance of the coupled system is enhanced by employing energy dissipative devices. These devices are activated by the rocking motion of the walls and are arranged throughout the building height, between the pinned-wall and the existing column. In [31], the coupling of an existing r.c. frame structure with a light-weight rocking frame equipped with a self-centering energy dissipative steel brace is presented, together with a design method for controlling the story stiffness demand. Dissipative braces located at the base of the rocking frame provide energy dissipation only for moderate or severe seismic actions, whereas for small actions the light-weight rocking frame adds stiffness but no damping to the existing structure.

This study focuses on the coupling of buildings with external dissipative rocking braced frames, centrally pinned at the foundation level, and equipped with dampers activated by the rocking motion. Similarly to pinned-rocking walls [32], [33], the proposed system is characterized by a high stiffness, allowing to linearize the displacement distribution along the height of the building and thus enforcing uniform interstorey drifts at the various storeys [34]. However, differently from pinned-rocking walls, it has an enhanced dissipation capacity, thanks to the added viscous dampers, and lower weight, due to the use of steel braces. This is a very important feature, as the self-weight of pinned rocking systems works against stability, thus resulting in large permanent displacements [32], [33].

The aim of this study is to investigate the effectiveness of dissipative towers for seismic retrofit of building frames. In particular, complex modal analysis is carried out to study the modal properties of the frame-tower coupled system, and the non-classical damping arising due to the concentration of the viscous dampers at the base of the tower, whereas a modal decomposition technique is employed to evaluate the seismic response of various response parameters while accounting for the contribution of higher order modes. For this purpose, a linear elastic assumption for both the tower and the frame is introduced, which however is accurate only in the case of enhanced performance levels and not very high seismic hazard levels.

This paper is organized in three sections. In the first one, the balance equations governing the linear problem are presented and a state space formulation is adopted to handle the non-classical damping and to obtain a solution of the seismic problem based on the modal decomposition method. The limit solution corresponding to the case of infinitely stiff tower is also discussed, and the properties of a single degree-of-freedom (SDOF) system equivalent to the multidegree-of-freedom (MDOF) coupled systems are derived, providing an insight into the system vibration and dissipative properties. In particular, the SDOF system properties are obtained by introducing a displacement constraint in the 
general formulation and they describe the limit case of rigid bracing and rigid floors. The section ends with a indications on a procedure that can be applied for the preliminary design of the dissipative devices. The second part of the paper focuses on the modal properties of the coupled system. A benchmark reinforced concrete frame widely analysed in the literature [35]-[39] is considered to illustrate the system structural properties, and different retrofit configurations are investigated. Two non-dimensional parameters are introduced: the former describes the relative stiffness of the external and protected frame and the latter depicts the added damping. They are used to evaluate the influence of the dissipative bracing characteristics on the dynamic properties of the non-classically damped system at hand. In the last part of the paper, the seismic response of the systems corresponding to the different retrofit scenarios is analysed by using the proposed formulation. The demand parameters considered in the analyses permit to evaluate the effect of the retrofit on the performance of the structural and non-structural building components, as well as of the dampers and the foundations.

\section{PROBLEM FORMULATION}

The system investigated in this study (Fig. 1 c) consists of a building frame connected at each floor level with one or more external braced frames. The external frame is supported by a spherical hinge and exhibits a rocking motion, which activates the vertical fluid viscous dampers (FVDs), located at the external frame base. This configuration is mainly oriented to make the inter-storey drift, and the relevant seismic damage, uniform along the building height, while the amplitude of the global response is controlled by a small number of dampers placed at the base only.

In the first part of this section, the equation of motion of the problem at hand is presented by assuming that both the building and the external damping system exhibit a linear response. The case of infinitely stiff tower is also presented, and the relevant balance equations of the reduced single-degree-of-freedom (SDOF) system are obtained by introducing a constraint in the structures' motion. Finally, the design procedure for the preliminary design of the dampers is presented. The reported formulation refers to the plane problem, and only the horizontal ground motion component is taken into account. A single equivalent external damping structure, representative of all the rocking frames activated along the monitored direction, is considered.

\subsection{Equation of motion}

The equation of motion of the system of Fig. 1c) can be expressed as follows:

$$
\mathbf{M} \ddot{\mathbf{u}}(t)+\mathbf{C u}(t)+\mathbf{K u}(t)=\mathbf{M p} a_{g}(t)
$$

where $\mathbf{u}(t) \in R^{l}$, is the vector of nodal displacements, the dot $(\cdot)$ denotes time-derivative; $\mathbf{p} \in R^{l}$ is the load distribution vector, $l$ denotes the total number of degrees-of-freedom, and $a_{g}(t)$ is the external scalar loading function describing the seismic base acceleration. The time invariant matrices $\mathbf{M}, \mathbf{K}, \mathbf{C}$ describe the mass, stiffness and damping operators $R^{l} \rightarrow R^{l}$; they result from the sum of the contributions of the existing frame and the external dissipative bracing system. Generally, the external bracing system significantly influences the stiffness and damping operators while it contributes only marginally to the mass operator. In order to shed light on this aspect, some simplifying assumptions are introduced to obtain a condensed system in which only the degrees of freedom of interest are made explicit [40]. The mass associated to the external bracing is considered null and the vector of the total displacement $\mathbf{u}(t)$ is split into the vector $\mathbf{x}(t) \in R^{m}$ and the vector $\mathbf{y}(t) \in R^{n}$, with $(l=m+n)$. The first one collects the active components of the displacements, namely related to inertia forces acting on the frame; the second, instead, describes the components connected to the internal degrees of freedom, including the bracing deformations providing the dampers displacements.

The matrices describing the linear operators and the load distribution vector can be accordingly partitioned as follows:

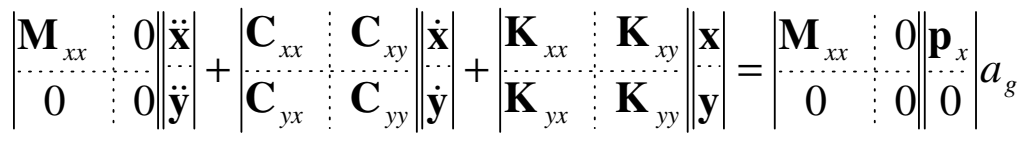

where $\mathbf{M}_{x x}$ is a diagonal mass matrix, containing the lumped floor masses.

In the following, the plane problem is considered, the floor diaphragms as well as tower-frame connections are assumed to be rigid, and inertia forces are associated only with lateral degrees of freedom. This way, the dimension $m$ of the vector $\mathbf{x}(t)$ coincides with the number of storeys of the building to protect, while the additional $n$ degrees of freedom of the vector $\mathbf{y}(t)$, describe the vertical displacements of the devices due to the rocking motion of the bracing base. Furthermore, the tower base motion described by $\mathbf{y}(t)$ induces an elastic deformation of the bracing and a set of reactions at the different levels of the building, collected into the submatrix $\mathbf{K}_{x y}$. Similarly, the displacements of the 
frame floors result in reactions at the bracing base, described by the submatrix $\mathbf{K}_{y x}=\mathbf{K}_{x y}^{T}$. Finally, the damper reactions due to the rocking motion of the external structure are collected into the matrix $\mathbf{C}_{y y}$.

The distribution of the damping in the structure and, in particular, the dampers concentrated at the base of the external bracing system, lead to a non-classically damped system, and the relevant problem solution can be conveniently found by resorting to a state-space approach. For this purpose, the vector $\mathbf{z}(t)$ is introduced, collecting the displacements and velocities of the active displacements, respectively $\mathbf{x}(t)$ and $\mathbf{v}(t)=\dot{\mathbf{x}}(t)$, and the displacements of the internal nodes $\mathbf{y}(t)$ :

$$
\mathbf{z}(t)=\left|\begin{array}{l}
\mathbf{x}(t) \\
\mathbf{v}(t) \\
\mathbf{y}(t)
\end{array}\right|
$$

Eqn. ( 1 ) can be reduced to the first order differential system of equations:

$$
\dot{\mathbf{z}}(t)=\mathbf{A z}(t)+\tilde{\mathbf{p}} a_{g}(t)
$$

where:

$$
\mathbf{A}=\left|\begin{array}{ccc}
\mathbf{0} & \mathbf{I} & \mathbf{0} \\
-\mathbf{M}_{x x}^{-1}\left(\mathbf{K}_{x x}-\mathbf{C}_{x y} \mathbf{C}_{y y}^{-1} \mathbf{K}_{y x}\right) & -\mathbf{M}_{x x}^{-1}\left(\mathbf{C}_{x x}-\mathbf{C}_{x y} \mathbf{C}_{y y}^{-1} \mathbf{C}_{y x}\right) & -\mathbf{M}_{x x}^{-1}\left(\mathbf{K}_{x y}-\mathbf{C}_{x y} \mathbf{C}_{y y}^{-1} \mathbf{K}_{y y}\right) \\
-\mathbf{C}_{y y}^{-1} \mathbf{K}_{y x} & -\mathbf{C}_{y y}^{-1} \mathbf{C}_{y x} & -\mathbf{C}_{y y}^{-1} \mathbf{K} y y
\end{array}\right|
$$

and where vector $\tilde{\mathbf{p}}$ is defined as:

$$
\tilde{\mathbf{p}}=\left|\begin{array}{c}
0 \\
\mathbf{M}_{x x}^{-1} \mathbf{p} \\
0
\end{array}\right|
$$

\subsection{Free vibrations and modal properties}

The free vibration problem, corresponding to posing $\tilde{\mathbf{p}}=\mathbf{0}$ in Eqn.( 4 ), can be solved by assuming a solution of the form $\mathbf{z}(t)=\boldsymbol{\varphi} e^{\lambda t}$, where $\lambda, \boldsymbol{\varphi}$ is a generic eigenvalue-eigenvector pair of the $(2 m+n)$-dimensional state matrix $\mathbf{A}$, such that:

$$
\mathbf{A} \varphi=\lambda \varphi
$$

In general, a complex eigenvalue has the following form

$$
\lambda_{i}=-\xi_{i} \omega_{0 i} \pm i \omega_{0 i} \sqrt{1-\xi_{i}^{2}}
$$

and contains information regarding both the damping ratio $\xi_{i}$ and the corresponding circular frequency $\omega_{0 i}$ of the $i$-th mode. These information can be extrapolated as follows:

$$
\begin{gathered}
\omega_{0 i}=\left|\lambda_{i}\right|=\sqrt{\left(\operatorname{Re}\left(\lambda_{i}\right)\right)^{2}+\left(\operatorname{Im}\left(\lambda_{i}\right)\right)^{2}} \\
\xi_{i}=-\operatorname{Re}\left(\lambda_{i}\right) / \sqrt{\left(\operatorname{Re}\left(\lambda_{i}\right)\right)^{2}+\left(\operatorname{Im}\left(\lambda_{i}\right)\right)^{2}}
\end{gathered}
$$

where $\operatorname{Re}\left(\lambda_{i}\right)=-\xi_{i} \omega_{0 i}$ and $\operatorname{Im}\left(\lambda_{i}\right)=\omega_{0 i} \sqrt{1-\xi_{i}^{2}}$ denote respectively the real and imaginary part of $\lambda_{i}$.

It is noteworthy that the eigenvalues are $(2 m+n)$ in total: $2 m$ of these are complex conjugates, and the remaining $n$ are real-valued and correspond to the motion of the degrees of freedom with no associated mass.

\subsection{Seismic response via modal decomposition method}

Having determined the modal properties, the problem solution can be obtained as a linear combination of the modal contributions. Let $\boldsymbol{\Lambda}$ be the diagonal matrix containing the complex eigenvalues and $\boldsymbol{\Phi}=\left|\boldsymbol{\varphi}_{1}, \boldsymbol{\varphi}_{2}, \ldots, \boldsymbol{\varphi}_{2 m+n}\right|$ the complex eigenmatrix containing the eigenvectors, such that the orthogonality property $\Lambda=\boldsymbol{\Phi}^{-1} \mathbf{A} \boldsymbol{\Phi}$ holds. The motion can be expressed as:

$$
\mathbf{z}(t)=\boldsymbol{\Phi q}(t)
$$

where $\mathbf{q}(t)$ is a vector collecting the modal coordinates. The orthogonality property leads to the diagonal problem: 


$$
\dot{\mathbf{q}}(t)=\Lambda \mathbf{q}(t)+\Gamma a_{g}(t)
$$

where $\boldsymbol{\Gamma}=\boldsymbol{\Phi}^{-1} \tilde{\mathbf{p}}$ is the vector collecting the complex-valued modal participation factors.

Introducing the normalized complex modal response vector $\mathbf{s}(t)$ such that: $q_{i}(t)=\Gamma_{i} s_{i}(t)$, the problem can be written in the following normalized form:

$$
\dot{\mathbf{s}}(t)=\mathbf{\Lambda} \mathbf{s}(t)+\mathbf{I} a_{g}(t)
$$

Assuming that the system is initially at rest, the solution is given by the Duhamel integral:

$$
\mathbf{s}(t)=\int_{0}^{t} \mathbf{h}(t-\tau) a_{g}(\tau) d \tau
$$

where the components $h_{i}(t)=e^{\lambda_{i} t}$ are the modal responses to an impulsive unitary input.

\section{$2.4 \quad$ Limit case of infinitely stiff tower}

In the case of an infinitely stiff tower (Fig. 2), all the degrees of freedom of the system, i.e., the horizontal floor displacements $\mathbf{x}(t)$, and the bracings motion $\mathbf{y}(t)$, are governed by a single parameter, identified as the base rotation $\gamma$. This is equivalent to introducing a constraint to the displacement field, and the displacement vector $\mathbf{u}(t)$ reduces to

$$
\mathbf{u}(t)=\mathbf{h} \gamma
$$

in which $\mathbf{h}$ is a vector collecting both the heights of the frame $\left(h_{i}\right.$, where $i=1, \ldots, n$ are the number of floors) and the width of the external bracing frame (i.e., $b / 2$ in Fig. 2). The D'Alembert Principle for the problem at hand can be expressed by introducing a virtual velocity field $\hat{\eta}=\mathbf{h} \hat{\gamma}$, in which $\hat{\gamma}$ is an arbitrary base rotation. Eqn. ( 1 ) can be rewritten for any time instant $t$ as

$$
\mathbf{M u ̈} \cdot \hat{\eta}+\mathbf{C}_{F} \dot{\mathbf{u}} \cdot \hat{\eta}+\mathbf{C}_{D} \dot{\mathbf{u}} \cdot \hat{\eta}+\mathbf{K u} \cdot \hat{\eta}=\mathbf{M p} \cdot \hat{\eta} a_{g} \quad \forall t, \forall \hat{\eta}
$$

where the matrix $\mathbf{M}$ collects masses of rigid floors, $\mathbf{K}$ is the stiffness matrix of the frame, $\mathbf{C}_{F}$ describes the damping of the frame and where $\mathbf{C}_{D}$ is the dissipative contribution of the dampers located at the tower base. Eqn. ( 15 ) can be rewritten as

$$
\tilde{m} \ddot{\gamma}+\left(\tilde{c}_{F}+\tilde{c}_{D}\right) \dot{\gamma}+\tilde{k} \gamma=m^{*} a_{g}
$$

where $\tilde{m}=\mathbf{M h} \cdot \mathbf{h}, \tilde{c}_{F}=\mathbf{C}_{F} \mathbf{h} \cdot \mathbf{h}, \tilde{c}_{D}=\mathbf{C}_{D} \mathbf{h} \cdot \mathbf{h}, \tilde{k}=\mathbf{K h} \cdot \mathbf{h}, m^{*}=\mathbf{M p} \cdot \mathbf{h}$ are the scalar parameters describing the properties of the system reduced to a SDOF, and $\cdot$ denotes the scalar product. By solving Eqn. ( 16 ), the time-history of the base rotation is known, and the vector of nodal displacements of the MDOF system is determined via Eqn. ( 14 ).

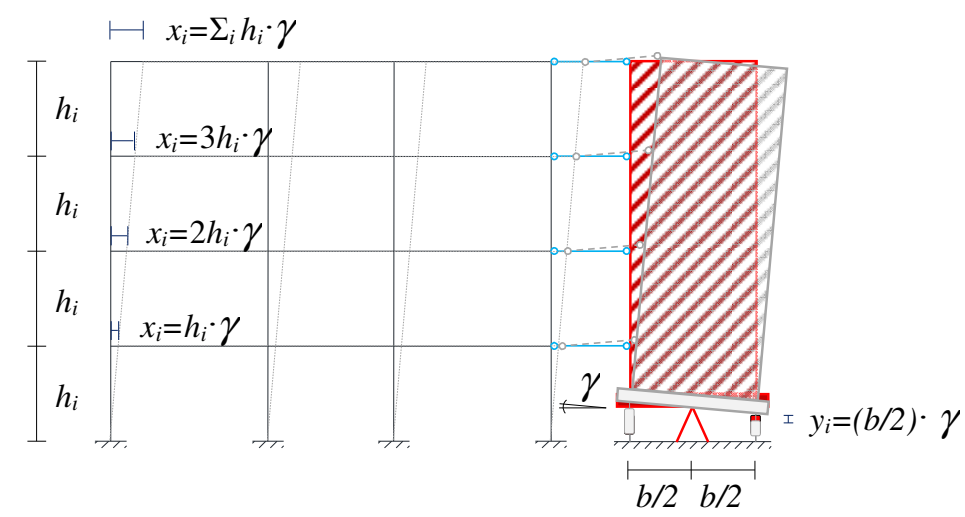

Fig. 2. Constrained motion of the system in the case of an infinitely rigid dissipative tower

The corresponding circular vibration frequency and added damping ratio due to the dampers located at the tower's base are:

$$
\omega_{r i g}^{2}=\frac{\varphi^{T} \mathbf{K} \boldsymbol{}}{\boldsymbol{\varphi}^{T} \mathbf{M} \boldsymbol{\varphi}}=\frac{\mathbf{h}^{T} \mathbf{K h}}{\mathbf{h}^{T} \mathbf{M h}}
$$




$$
\xi_{\text {add }, \text { rig }}=\frac{c_{d} N_{d} b^{2} / 4}{2 \omega \mathbf{h}^{T} \mathbf{M h}}
$$

where $c_{d}$ is the viscous constant of the $N_{d}$ dampers located at the tower base. Eqn. ( 17 ) and ( 18 ) provide closed-form estimates of the changes of the dynamic properties of the system due to the dissipative towers and can be quite useful as very often the external towers are quite rigid. In the next section, the approximation of rigid tower behaviour is evaluated by considering different retrofit configurations.

\subsection{Preliminary design of the dissipative system}

The preliminary design of the linear FVDs, located at tower base, can be carried out by assuming that the coupled frame-tower system, which is non classically-damped, vibrates according to the first undamped mode of vibration. The results of the following parametric analyses, described in Section 3.2 and subsequent ones, provide some useful suggestions about the optimal stiffness value of the added tower. First of all, a modal analysis is performed to determine both the first natural frequency $\omega_{01}$ and the corresponding modal shape $\boldsymbol{\psi}_{1}$. Then, a design value of the target displacement of the system can be fixed, and the required added damping ratio $\boldsymbol{\xi}_{\text {add }}$ due to the viscous dampers can be evaluated, e.g. by employing the capacity spectrum method [41]. The viscous damping constants corresponding to the required value of $\xi_{\text {add }}$ can then be evaluated by using the general expression of ASCE 41-13 [42]:

$$
\xi_{\text {add }}=\frac{\sum_{j=1}^{N} E_{j}}{4 \pi E_{f}}
$$

where $E_{j}$ is the work done by $j$-th device in one complete vibration cycle at the fundamental frequency of the coupled system, and $E_{f}$ is the maximum strain energy attained by the system in the cycle.

This expression can be specialized to the case of dampers having the same properties, and can be rearranged to provide the viscous constant $c_{d}$ of the dampers in function of $\xi_{\text {add }}$ as follows:

$$
c_{d}=\xi_{\text {add }} \frac{4 \pi \sum_{i} m_{i} \delta_{i}^{2}}{T \sum_{j} \bar{\delta}_{j}^{2}}
$$

where $m_{i}$ denotes the $i$-th floor lumped mass, $\delta_{i}$ is the modal displacement of the $i$-th floor and $\bar{\delta}_{j}$ the modal displacement of the $j$-th viscous damper.

\section{STRUCTURAL RESPONSE}

\subsection{Benchmark structure}

In this section, the formulation presented above is employed to analyse the influence of the rocking tower on the seismic performance of a building structure which has been extensively studied in the literature [35]-[39]. This benchmark case study is a 7-storey reinforced-concrete frame (Fig. 3) located in Van Nuys, California; it consists of perimeter moment frames and interior slab-column frames ( 3 bays-by- 8 bays), with non ductile behaviour, having been designed in 1965 in compliance to the lateral force requirements of 1964 Los Angeles City Building Code. Detailed descriptions including dimensions and member sizes are provided in many other works [35]-[39].

The original state of the building before the upgrading works carried out after 1994 Northridge earthquake is considered. Different retrofit configurations are evaluated in the following, with the steel towers arranged as reported in Fig. 3 a). The number of towers derives from feasibility issues and it is related to the total amount of stiffness required. In accordance to the proposed formulation, the plane problem described in Fig. $3 \mathrm{~b}$ ) is considered.

Under the assumptions discussed in the previous section, only the seven floor displacements need to be considered in the vector of active degrees of freedom $\mathbf{x}(t) \in R^{m}$, while the vector $\mathbf{y}(t) \in R^{n}$ collects the displacements of the FVDs along the vertical direction. The damping matrix $\mathbf{C}$ is built by assuming a Rayleigh damping model, providing an inherent damping ratio $\xi=0.05$ at the first two vibration modes of the coupled system.

Having determined the terms of Eqn. ( 1 ), the numerical solution to the dynamic and seismic problem for the coupled system is evaluated by employing MATLAB [43]. 

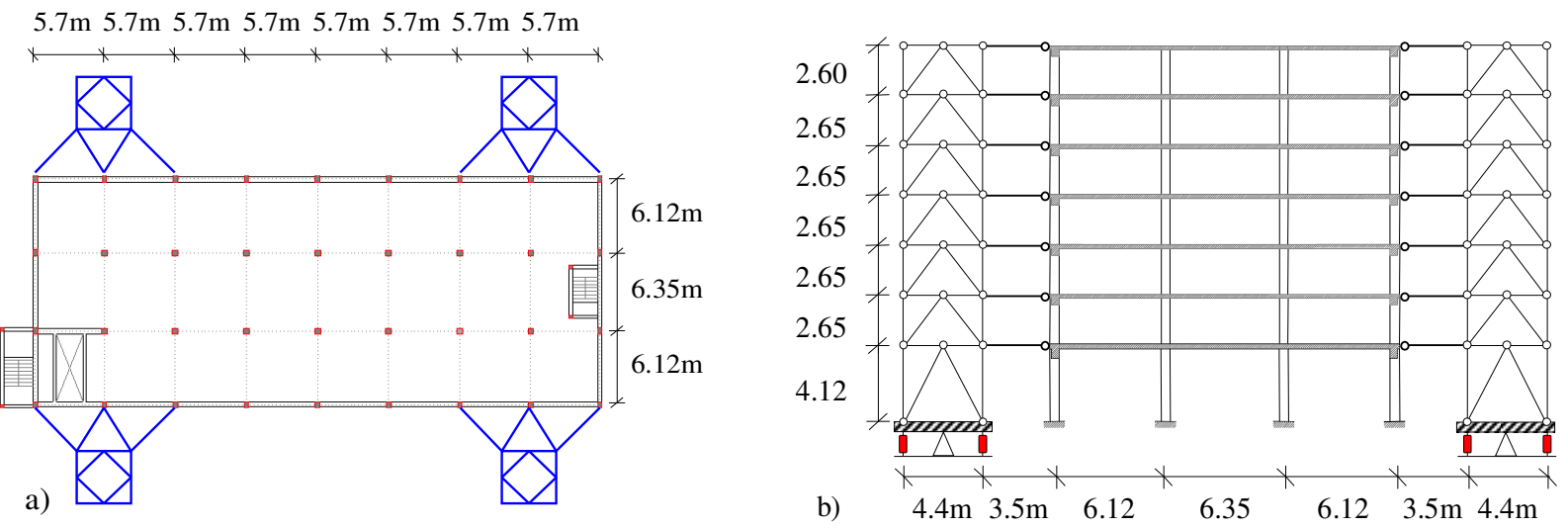

Fig. 3. Planar view a) and horizontal section b) of the building in one of the analysed retrofit configurations

\subsection{Parametric analysis and hazard scenario description}

In order to understand how the added stiffness and damping due to the tower influence the seismic performance of the coupled system, a parametric study is carried out by varying the tower stiffness and damper viscous constant and by evaluating the corresponding changes in the dynamic properties and seismic response.

Two non-dimensional parameters are used to synthetically describe the contribution of the tower to the stiffness and damping. The first one is $\kappa=K_{T} / K_{F}$, denoting the tower-to-frame stiffness ratio, where the stiffness measures for the frame and the tower, respectively $K_{F}$ and $K_{T}$, are evaluated by imposing a unit horizontal displacement at their top and by evaluating the corresponding base reaction. In the case of the tower, a fixed base condition is considered, in order to cut off the rigid motion due to the rocking displacements. The second parameter is $\xi_{\text {add }}$, an estimate of the damping added to the first mode of vibration of the coupled system, evaluated according to Eqn. ( 19 ).

In the analyses, different configurations are considered, corresponding to values of $\kappa=1$ and $\kappa=0.5$. In addition, also the case $K=\infty$ corresponding to an infinitely stiff tower (denoted as Stiff) is considered for comparison purposes. The two retrofit configurations considered, corresponding to $\kappa=1$ and $\kappa=0.5$, are obtained with a different number of towers having the same size and equal members, that is four towers for $\kappa=1$ and two towers for $\kappa=0.5$. Table 1 reports the cross-section properties employed for the braces forming the towers. The members' cross-sections satisfy the EC3 code requirements [44] for the buckling resistance of members subjected to uniform compression. The safety checks have been carried out by considering the mean values of the maxima evaluated for the various ground motion records representing the seismic input, as described below. The values considered for the added damping $\xi_{\text {add }}$ span in the range between 0 and 0.3. The case of the bare existing frame (denoted to as Uncontrolled configuration) correspond to $K=0 ; \xi_{\text {add }}=0$.

Table 1. Bracing geometrical properties for the investigated configurations

\begin{tabular}{c|ccccccc} 
Floor & 1 & 2 & 3 & 4 & 5 & 6 & Roof \\
\hline column & HE300B & HE200B & HE180B & HE160B & HE160B & HE160B & HE160B \\
brace & HE300B & HE200B & HE180B & HE160B & HE160B & HE160B & HE160B
\end{tabular}

The seismic scenario is described by 20 ground motions taken from those employed in the SAC project from the joint venture of the Structural Engineers Association of California, the Applied Technology Council and California Universities for Research in Earthquake Engineering [45], representative of the Los Angeles area, and characterized by a probability of exceedance of $10 \%$ in 50 years. The selected ground motions exhibit different seismic intensity, frequency content and duration. Fig. 4 reports the pseudo-acceleration response spectra of these 20 records together with the mean response spectrum. In the same figure, the spectral value at the first vibration period of the bare frame in the horizontal direction is also highlighted by a circle. 


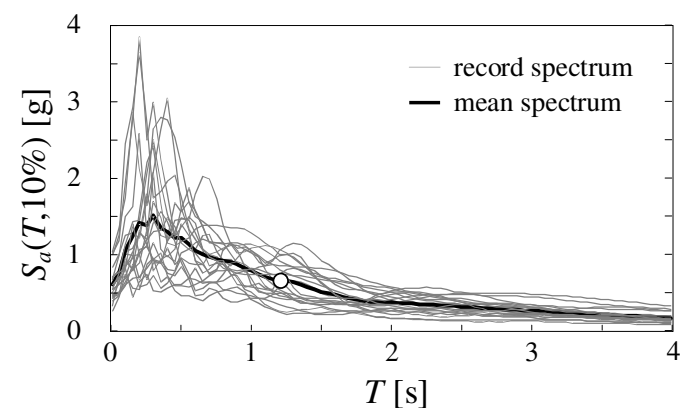

Fig. 4. Pseudo-acceleration response spectra describing the seismic scenario

\subsection{Modal properties of the undamped coupled system}

This section analyses the influence of the bracings stiffness on the modal properties of the coupled system. For this purpose, three values of the parameter $\kappa$ are considered: $\kappa=0$ (Uncontrolled case), $\kappa=0.5$ and $\kappa=1$. The influence of the added damping is studied in the following and the results presented in this section concern the case $\left(\xi_{\text {add }}=0\right)$.

Table 2 reports the vibration periods, the undamped natural frequencies and the participant mass ratios $M_{i}^{*}$ of the bare building and of two retrofit configurations corresponding to $K=1$ and $K=0.5$. The participant mass ratio is defined as $M_{i}^{*}=\left(\mathbf{M p} \cdot \boldsymbol{\psi}_{i}\right)^{2} / \mathbf{M} \boldsymbol{\psi}_{i} \cdot \boldsymbol{\psi}_{i}$ where $\boldsymbol{\psi}_{i}$ are the eigenvectors of the undamped system.

Table 2. Modal analysis results of the bare building and of the retrofitted building

\begin{tabular}{|c|c|c|c|c|c|c|c|c|c|c|c|}
\hline \multicolumn{4}{|c|}{ Uncontrolled $(\kappa=0)$} & \multicolumn{4}{|c|}{ Retrofit $(\kappa=0.5)$} & \multicolumn{4}{|c|}{ Retrofit $(K=1)$} \\
\hline$T_{i}[\mathrm{~s}]$ & $\omega_{0}[\mathrm{rad} / \mathrm{s}]$ & $M_{i}^{*}[-]$ & $\Sigma M_{i}^{*}[-]$ & $T_{i}[\mathrm{~s}]$ & $\omega_{0}[\mathrm{rad} / \mathrm{s}]$ & $M_{\mathrm{i}}^{*}$ & $\Sigma M_{\mathrm{i}}^{*}$ & $T_{i}[\mathrm{~s}]$ & $\omega_{0}[\mathrm{rad} / \mathrm{s}]$ & $M_{\mathrm{i}}^{*}$ & $\Sigma M_{\mathrm{i}}^{*}$ \\
\hline 1.204 & 5.22 & 0.831 & 0.831 & 1.182 & 5.32 & 0.833 & 0.833 & 1.177 & 5.34 & 0.832 & 0.832 \\
\hline 0.391 & 16.06 & 0.118 & 0.949 & 0.302 & 20.77 & 0.120 & 0.953 & 0.257 & 24.46 & 0.122 & 0.954 \\
\hline 0.218 & 28.86 & 0.035 & 0.984 & 0.151 & 41.62 & 0.032 & 0.985 & 0.123 & 51.11 & 0.031 & 0.985 \\
\hline 0.138 & 45.61 & 0.011 & 0.995 & 0.097 & 64.85 & 0.010 & 0.995 & 0.079 & 79.31 & 0.010 & 0.995 \\
\hline 0.093 & 67.34 & 0.003 & 0.998 & 0.07 & 89.48 & 0.003 & 0.998 & 0.059 & 106.8 & 0.003 & 0.999 \\
\hline 0.068 & 91.94 & 0.001 & 1 & 0.054 & 115.4 & 0.001 & 1 & 0.047 & 134.3 & 0.001 & 1 \\
\hline 0.056 & 112.42 & 0 & 1 & 0.046 & 135.3 & 0 & 1 & 0.041 & 154.6 & 0 & 1 \\
\hline
\end{tabular}

In general, it can be observed that the coupling with the tower does not affect significantly the first vibration period. In fact, its reduction, with respect to the bare frame case, is of about $2.2 \%$ in the case of the towers with stiffness ratio $\kappa=1$ and of about $1.9 \%$ in the case of the towers with stiffness ratio $\kappa=0.5$. The variation of the second vibration period is higher, in fact in the case of $\kappa=1$ the reduction, with respect to the bare frame, is nearly $34.3 \%$, while in the case of $K=0.5$ the reduction is nearly $22.7 \%$. Similar notable variations are observed in the successive modes. In all the cases, the first two vibration modes involve more than $95 \%$ of the total participating mass, with minor variations due to the addition of the towers. The case of the existing frame coupled with an infinitely stiff tower yields a fundamental period of $T=1.149 \mathrm{~s}$, corresponding to the highest reduction (4.8\%) with respect to the other cases.

Fig. 5 reports the values of the interstorey drifts along the building height for the first three vibration modes. The results obtained for the bare building are compared with results obtained for the coupled system with $\kappa=1$ and $K=0.5$ and $\kappa=\infty$, only for the first mode. The interstorey drift values are derived from the displacements distribution along the height, with the maximum top displacement normalized to unity. It can be observed that the addition of the towers yields a regularization of the first mode drift distribution along the building height, corresponding to an increase of the drift at some levels and a decrease at the other levels with respect to the case of the bare frame. The case $\kappa=\infty$ yields the best result in terms of uniform distribution of interstorey drifts, and the case corresponding to $\kappa=1$ provides quite similar results.

Fig. 6 reports the distribution of the shear force resisted by the frame in the Uncontrolled and in the retrofit cases, for the first three vibration modes. These modal results are normalized by posing the base shear equal to 1.0. Also in this case, the coupling results in a more uniform distribution of the storey shear of the first mode, with an increase at some storey levels and a decrease at the others. As already seen for the interstorey drifts, the case corresponding to $\kappa=\infty$ provides similar results with respect to the case of $\kappa=1$. 


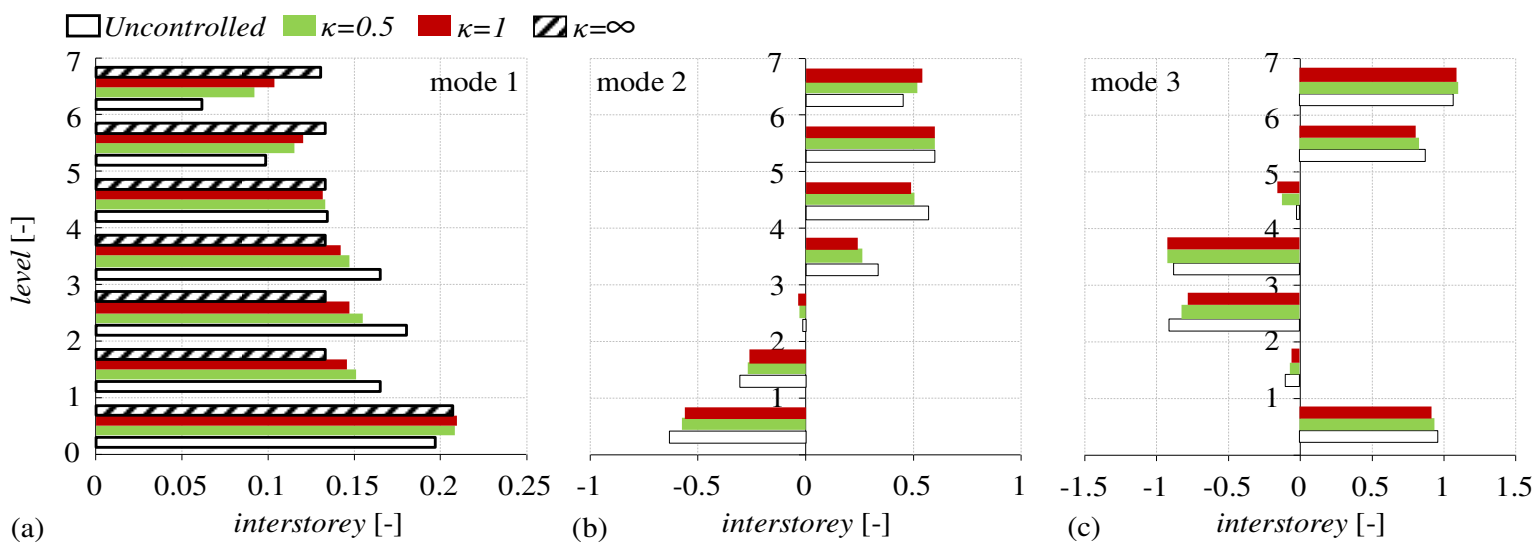

Fig. 5. Interstorey drifts along the building height for different values of $\kappa:$ (a) mode 1 , (b) mode 2 and (c) mode 3
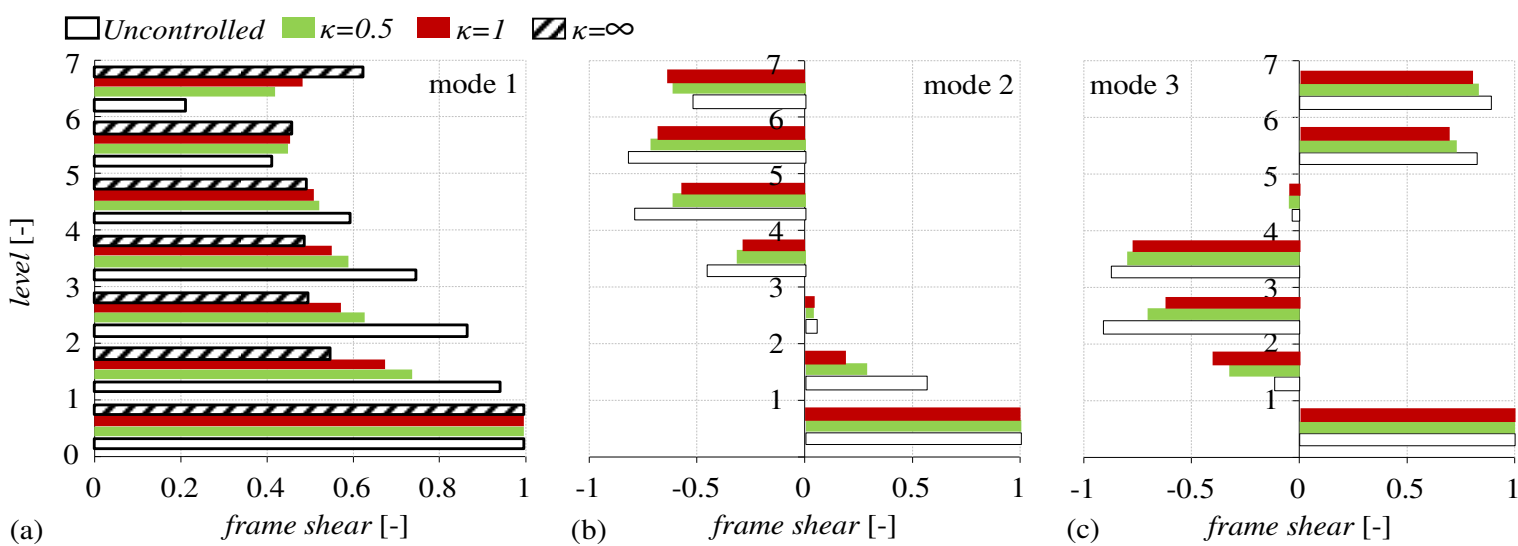

Fig. 6. Frame shear forces along the building height for different values of $\kappa:$ (a) mode 1, (b) mode 2 and (c) mode 3

Fig. 7 compares the total storey shear distribution with the separate contribution due to the frame and the bracing. Reported results concern the retrofit case with $K=1$, which is the reference configuration for the retrofit. It is worth to note that the shear contribution of the existing frame and of the tower have different signs at some levels and the frame storey shear can be larger than the total storey shear. This might constitute a drawback in the seismic response.
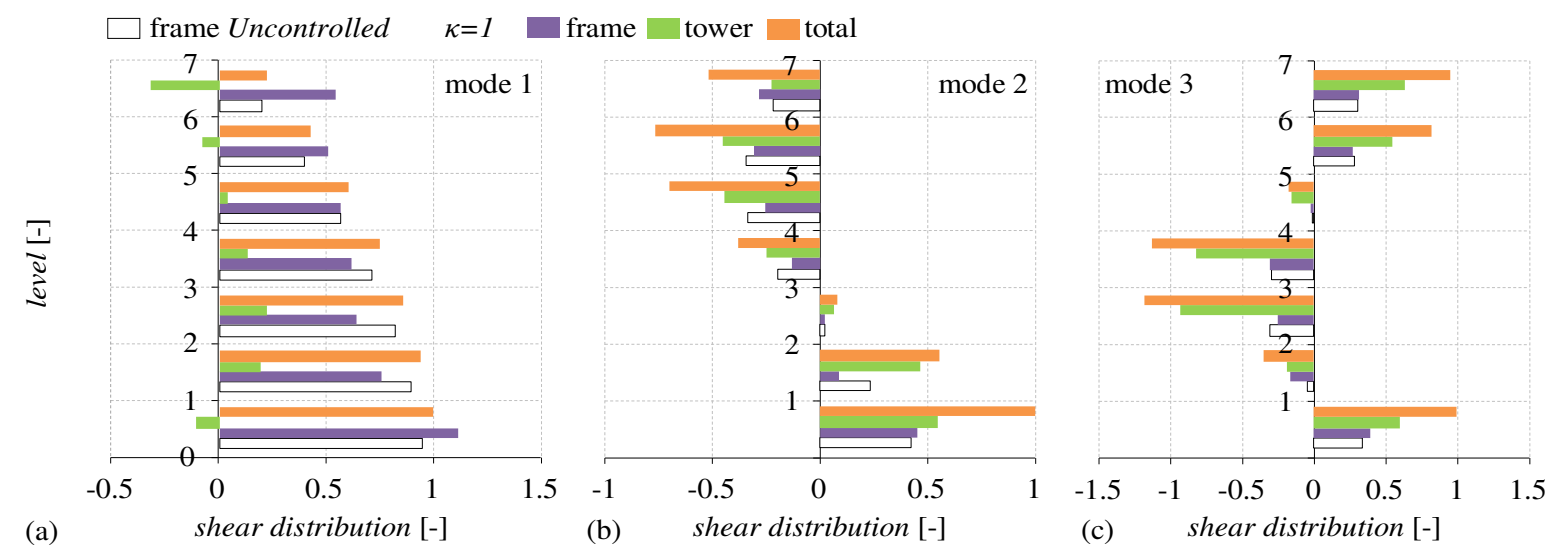

Fig. 7. Shear force distribution for mode 1 (a), mode 2 (b) and 3 (c) $-\kappa=1$ case

\subsection{Modal properties of the coupled damped system}

In this section, the influence of non-classical added damping on the dynamic properties of the system is studied. The variation of the modal properties at different damping levels is evaluated via complex modal analysis by considering values of the added damping factor $\xi_{\text {add }}$ in the range between 0 and 0.9 .

Fig. 8 (a) and (b) show the influence of $\xi_{\text {add }}$ on the vibration periods of the first three modes of two retrofit configurations corresponding, respectively, to $\kappa=1$ and to $\kappa=0.5$. These periods are obtained from the expression 
$2 \pi / \omega_{0 i}$ for $i=1,2,3$, where $\omega_{0 i}$ is evaluated via Eqn. ( 9 ). In the same figures, the vibration periods corresponding to the classically-damped system with no added dampers (referred to as "undamped" in the legend) are shown for comparison purposes. In general, the vibration periods of the coupled system decrease by increasing the damping level but, on both the two cases, only the first vibration period of the system is significantly affected by the added damping. For $\xi_{\text {add }}=0.9$, in the retrofit $\kappa=1$ case, the first period attains the value $0.731 \mathrm{~s}(62 \%$ of the value observed for undamped case), the second $0.222 \mathrm{~s}$ ( $86 \%$ of the related undamped period), and a negligible variation is observed in the third period, which is equal to $0.118 \mathrm{~s}$ ( $96 \%$ of the related undamped period). Similar considerations can be done for the case $K=0.5$. Fig. 8 (a) and (b) show also the results obtained for $K=\infty$. It is observed that the assumption of infinitely stiff tower provides quite accurate estimates of the fundamental period for low added damping values.

Fig. 9 (a) and (b) report the variation of the damping ratio of the first, second and third vibration modes of the same two retrofit configurations $(\kappa=1$ and to $\kappa=0.5$ ). The trends of the damping ratios are very similar for the two retrofit configurations, with higher variations observed for the first two modes, and negligible variation for the third one. In both cases, the first modal damping ratio $\left(\xi_{1}\right)$ is well approximated by the design formula of Eqn. ( 19$)$ for value of $\xi_{\text {add }}$ up to 0.3 in the case of $\kappa=1$ and up to 0.15 in the case of $\kappa=0.5$. For values increasing beyond these limits, the amount of the effective damping decreases. As already observed for the periods, the influence of the damper dimensions on the second and third mode is less notable; for the $K=1$ configuration the damping ratio varies in the range 0.050 0.089 with a maximum of 0.135 when $\xi_{\text {add }}$ reaches the value of 0.25 for the second mode, while for the third mode the range is $0.090-0.099$ with a maximum value of 0.110 when $\xi_{\text {add }}=0.15$. For the $\kappa=0.5$ case the trend is very similar, the second mode has its maximum, 0.111 , for the design value of $\xi_{\text {add }}=0.15$, while the damping ratio varies in the range 0.050-0.085. Finally, the range of variation of the third mode is $0.085-0.092$ with a maximum value of 0.100 at $\xi_{\text {add }}=0.1$. The results obtained by considering $\kappa=\infty$ are also reported in Fig. 9, showing that the assumption of infinitely stiff tower provides accurate estimates of the added damping of the fundamental mode for both the configurations ( $K=1$ and to $K=0.5$ ).
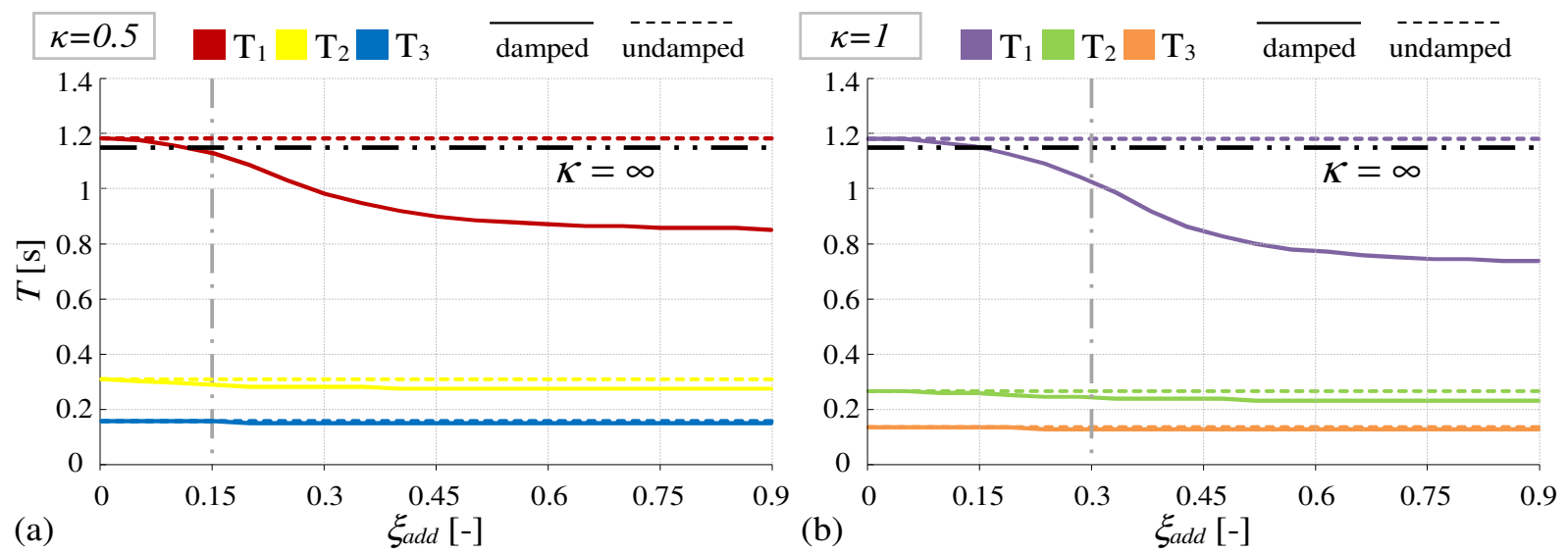

Fig. 8. Variation with $\xi_{\text {add }}$ of the first three periods obtained in the undamped and the damped case for $\kappa=0.5$ (a) and $\kappa=1(\mathrm{~b})$
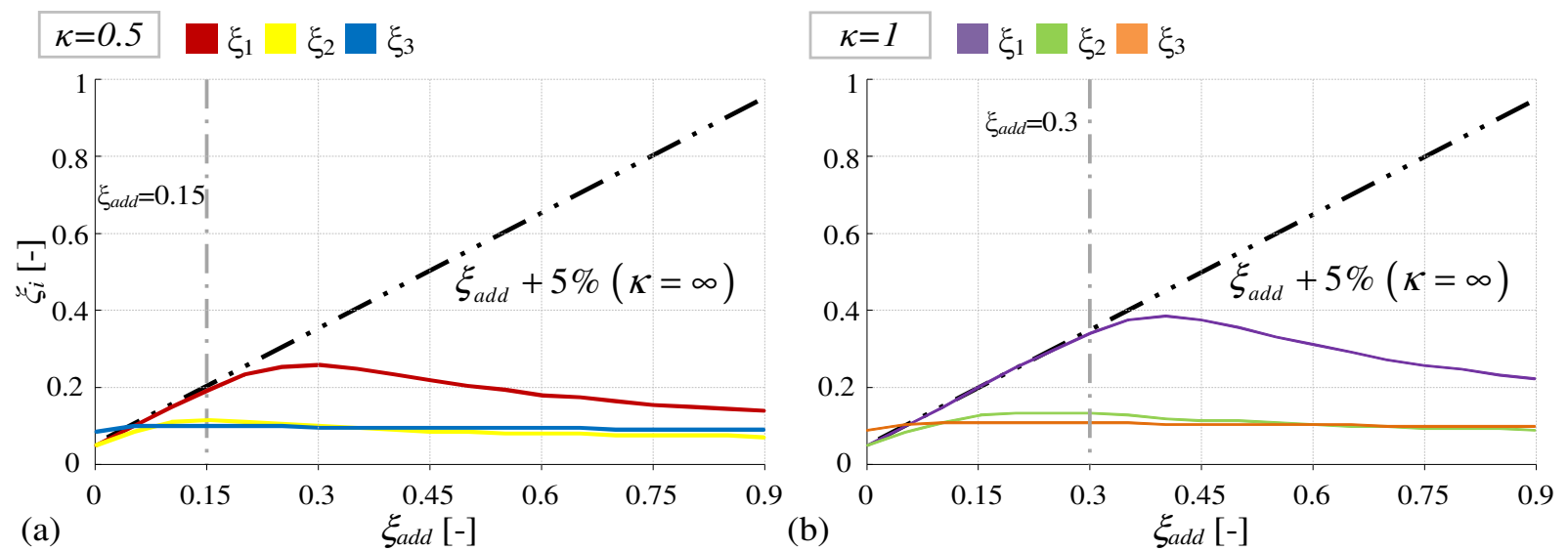

Fig. 9. Variation with $\xi_{\text {add }}$ of the damping ratio $\xi_{i}$ of the first three modes obtained for $\kappa=0.5$ (a) and $\kappa=1$ (b) 
Due to the fact that all the dampers are concentrated at the tower base the system is non-classical damped and the extent of non-classical damping can be synthetically quantified by the coupling index $\rho$ [46], expressed as:

$$
\rho=\max _{i, j=1 . . m, \mathrm{i} \neq \mathrm{j}}\left|\frac{\Xi_{i j}^{2}}{\Xi_{i i} \Xi_{j j}}\right|
$$

where $\Xi_{i j}=\boldsymbol{\psi}_{i}^{T} \mathbf{C} \boldsymbol{\psi}_{j}(\mathrm{i}, \mathrm{j}=1,2, \ldots, m)$ represents the coupling between the responses of mode $i$ and $j$, and $\boldsymbol{\psi}_{i}$ are the eigenvectors of the undamped system.

In general, $\rho$ assumes values in the interval $[0,1]$ and it is equal to zero for a classically damped system. Fig. 10 (a) reports the values assumed by the coupling index for the two different retrofit configurations for increasing damping levels. It can be seen that $\rho$ increases less than linearly for increasing values of $\xi_{\text {add }}$ and that the two retrofit cases provide nearly the same values of the index. Fig. 10 (b) shows the values of $\Xi_{i j}$ obtained for the case $K=1$ and $\xi_{\text {add }}=0.3$. In particular, for $\xi_{\text {add }}=0.3, \Xi_{12}=0.68$ and it coincides with the coupling index $\rho$, i.e., the coupling is highest between the first and the second mode of vibration with respect to the other modes.

Fig. 11 shows the first three modal shapes of the coupled system with $\kappa=1$, for different levels of $\boldsymbol{\xi}_{\text {add }}$. The real and imaginary components of the complex eigenvectors $\boldsymbol{\varphi}_{i}$ are plotted separately and normalized in such a way that the first component of the real part of the eigenvector $\boldsymbol{\varphi}_{i}$ is equal to one, while the corresponding imaginary part is equal to zero. In the case of $\xi_{a d d}=0$, the system is classically damped, and the eigenvectors are real. Increasing the damping level affects significantly the first mode, while the higher modes are less influenced by $\xi_{\text {add }}$.

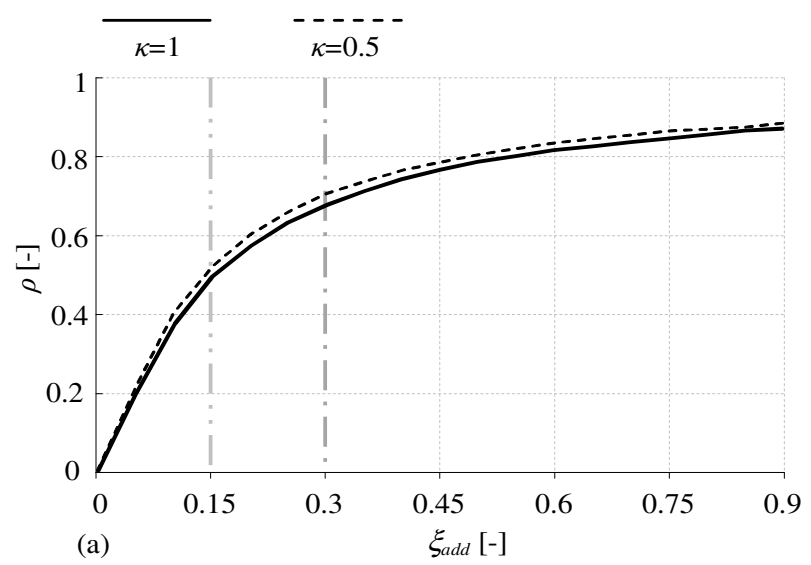

\begin{tabular}{|c|c|c|c|c|c|c|c|}
\hline \multirow{5}{*}{ 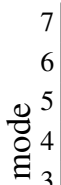 } & 0 & 0 & 0 & 0 & 0 & 0 & 1 \\
\hline & 0 & 0 & 0 & 0 & 0 & 1 & 0 \\
\hline & 0.02 & 0.02 & 0.01 & 0 & 1 & 0 & 0 \\
\hline & 0.08 & 0.08 & 0.04 & 1 & 0 & 0 & 0 \\
\hline & 0.40 & 0.37 & 1 & 0.04 & 0.01 & 0 & 0 \\
\hline 2 & 0.68 & 1 & 0.37 & 0.08 & 0.02 & 0 & 0 \\
\hline 1 & 1 & 0.68 & 0.40 & 0.08 & 0.02 & 0 & 0 \\
\hline & 1 & 2 & 3 & $\begin{array}{c}4 \\
\bmod \end{array}$ & 5 & 6 & 7 \\
\hline
\end{tabular}

(b)

Fig. 10. (a) Variation with $\xi_{\text {add }}$ of the coupling index $\rho$ for $\kappa=1$ and $\kappa=0.5$; (b) Matrix showing the values of $\Xi_{i j}$ for the seven modes of the system for $\kappa=1$ and $\xi_{\text {add }}=0.3$

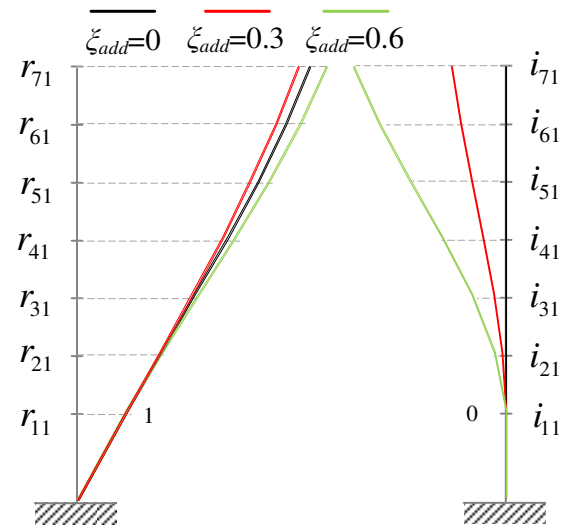

(a)

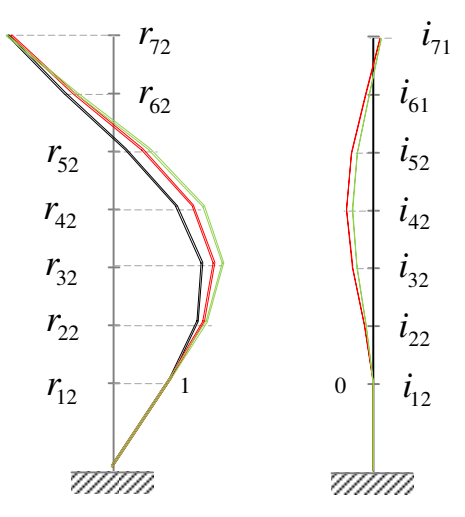

(b)

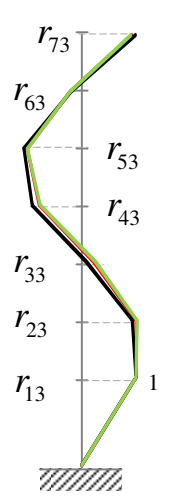

(c)

Fig. 11. Real and imaginary part of the complex eigenvectors of the retrofit configuration corresponding to $K=1$ for increasing values of $\xi_{\text {add }}$ : (a) first mode (b) second mode (c) third mode 


\subsection{Seismic Response}

This section compares the seismic response of the bare frame with the seismic response of a set of retrofit configurations involving different values of the relative stiffness $\kappa$ and added damping $\xi_{\text {add }}$. The reported results concern the engineering demand parameters (EDPs) of major interest for the performance assessment of the frame and the tower (i.e., displacements, inter-storey drifts, storey shear actions, absolute accelerations) and of the viscous dampers (displacements, velocities, forces). The values of EDPs reported below are the mean of the maximum values obtained for each of the twenty time-histories considered. The following five configurations are studied: the case $K=0$ and $\xi_{\text {add }}=0$, denoted as Uncontrolled case, the case $\kappa=0.5$ and $\xi_{\text {add }}=0.15$, the case $K=1$ and $\xi_{\text {add }}=0.15$, the case $\kappa=1$ and $\xi_{\text {add }}=0.3$, the S-DOF limit case with stiff bracings and $\xi_{\text {add }}=0.3$, denoted as Stiff case.

Table 3 reports the floor displacements $x_{i}$ and the inter-storey drift (IDR) $\vartheta_{i}$ for the five configurations analysed. Displacement values are normalized with respect to the maximum displacement at the top of the bare frame that is equal to $30.6 \mathrm{~cm}$. The frame undergoes significant displacements with a maximum interstorey drift ratio (IDR) of $2.07 \%$ attained at the third storey. The deformation values observed for the bare frame is usually associated with a large structural damage. The retrofit reference configuration corresponding to $\kappa=1$ and $\xi_{\text {add }}=0.3$ leads to a notable reduction of the global deformation and the maximum displacements demand is equal to $15.8 \mathrm{~cm}$, corresponding to the $52 \%$ of the bare frame maximum displacement. A more evident reduction can be observed in the local deformation at storey level: the maximum IDR demand is equal to $0.89 \%$, corresponding to $43 \%$ of the bare frame IDR. The maximum reduction is observed in the limit case Stiff providing a maximum IDR equal to $0.72 \%$. It is noteworthy that these IDR values are associated to a moderate damage of the non-structural components [47] and are below the elastic limit of the structural components [35], which justifies a linear elastic model for the frame.

Fig. 12 (a) and (b) depicts the distribution of the previous results and gives evidence to the more regular distribution of IDRs at storeys.

Table 3. Floor displacements and drifts for the various configurations analysed

\begin{tabular}{ccccccccccc}
\hline \multirow{2}{*}{ level } & \multicolumn{2}{c}{ Uncontrolled } & \multicolumn{2}{c}{$\kappa=0.5 ;$} & $\xi_{\text {add }}=0.15$ & \multicolumn{2}{c}{$\kappa=1 ;$} & $\xi_{\text {add }}=0.15$ & \multicolumn{2}{c}{$\kappa=1 ;$} \\
& $x_{i}[\mathrm{~m}]$ & $\theta_{i}[\%]$ & $x_{i}[\mathrm{~m}]$ & $\theta_{i}[\%]$ & $x_{i}[\mathrm{~m}]$ & $\theta_{i}[\%]$ & $x_{i}[\mathrm{~m}]$ & $\theta_{i}[\%]$ & $x_{i}[\mathrm{~m}]$ & $\theta_{i}[\%]$ \\
\hline 1 & 0.063 & 1.52 & 0.040 & 0.96 & 0.040 & 0.97 & 0.031 & 0.75 & 0.030 & 0.72 \\
2 & 0.113 & 1.90 & 0.069 & 1.11 & 0.068 & 1.06 & 0.053 & 0.84 & 0.049 & 0.72 \\
3 & 0.165 & 2.07 & 0.099 & 1.17 & 0.096 & 1.09 & 0.076 & 0.88 & 0.068 & 0.72 \\
4 & 0.213 & 1.98 & 0.129 & 1.16 & 0.124 & 1.07 & 0.098 & 0.89 & 0.087 & 0.72 \\
5 & 0.253 & 1.72 & 0.156 & 1.10 & 0.150 & 1.03 & 0.120 & 0.88 & 0.106 & 0.72 \\
6 & 0.285 & 1.35 & 0.180 & 0.99 & 0.174 & 0.96 & 0.141 & 0.84 & 0.125 & 0.72 \\
7 & 0.306 & 0.91 & 0.201 & 0.83 & 0.195 & 0.85 & 0.158 & 0.74 & 0.144 & 0.72 \\
\hline
\end{tabular}
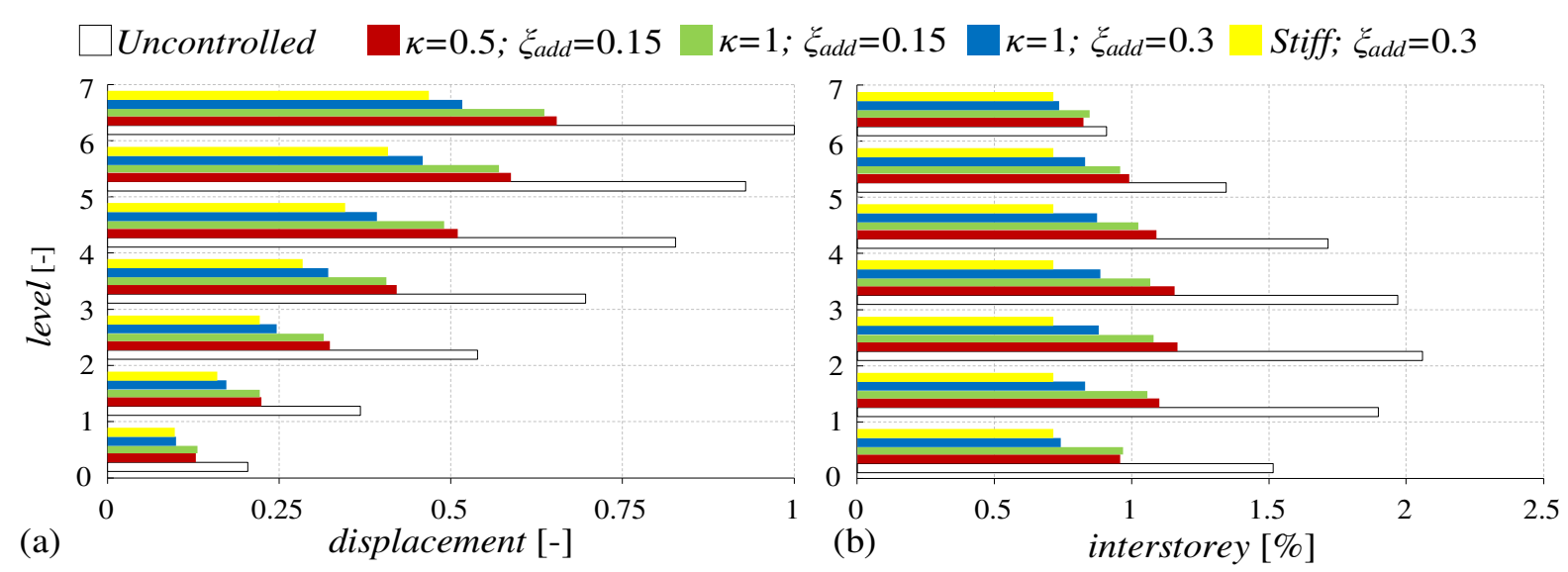

Fig. 12. Displacements (a) and interstorey drifts (b) distributions for the for the various configurations analysed

In order to analyse the contribution of the first vibration mode with respect to the contribution of the higher modes in the seismic response, the full response, considering all the vibration modes, is compared with the response obtained by the first mode only. Table 4 reports the displacement response for the Uncontrolled case and different retrofit configurations. As expected, the displacements are mainly controlled by the first mode, but the contributions of higher modes become almost negligible in all the retrofit cases. 
Table 4. Higher order modes contribution to floor displacements for the various configurations analysed

\begin{tabular}{cccccccccc}
\hline \multirow{2}{*}{ level } & \multicolumn{2}{c}{ Uncontrolled } & \multicolumn{2}{c}{$\kappa=0.5 ; \xi_{\text {add }}=0.15$} & \multicolumn{2}{c}{$\kappa=1 ; \xi_{\text {add }}=0.15$} & \multicolumn{2}{c}{$\kappa=1 ; \xi_{\text {add }}=0.3$} \\
& $x_{\text {full }}[\mathrm{m}]$ & $x_{1}[\mathrm{~m}]$ & $x_{\text {full }}[\mathrm{m}]$ & $x_{1}[\mathrm{~m}]$ & $x_{\text {full }}[\mathrm{m}]$ & $x_{1}[\mathrm{~m}]$ & $x_{\text {full }}[\mathrm{m}]$ & $x_{1}[\mathrm{~m}]$ \\
\hline 1 & 0.063 & 0.059 & 0.040 & 0.040 & 0.040 & 0.040 & 0.031 & 0.032 \\
2 & 0.113 & 0.109 & 0.069 & 0.069 & 0.068 & 0.068 & 0.053 & 0.053 \\
3 & 0.165 & 0.163 & 0.099 & 0.100 & 0.096 & 0.097 & 0.076 & 0.076 \\
4 & 0.213 & 0.213 & 0.129 & 0.129 & 0.124 & 0.124 & 0.098 & 0.098 \\
5 & 0.253 & 0.253 & 0.156 & 0.156 & 0.150 & 0.150 & 0.120 & 0.120 \\
6 & 0.285 & 0.283 & 0.180 & 0.180 & 0.174 & 0.174 & 0.141 & 0.140 \\
7 & 0.306 & 0.301 & 0.201 & 0.199 & 0.195 & 0.195 & 0.158 & 0.157 \\
\hline
\end{tabular}

In general, the base shear of the frame is reduced in all the retrofit scenarios with respect to the bare-frame case, and the base shear of the tower is lower than that of the frame. However, in some cases ( $\kappa=1 ; \xi_{\text {add }}=0.30$ and Stiff), the base shear resisted by the tower is very high and similar in value to the one of the frame. This may have an impact on the cost of the foundations of the tower.

The addition of the towers generally results in a reduction of the global shear demand at all the levels. A quite more complex behaviour can be observed for the shear forces in the frame, where two opposite contributions acts: on one hand, the increasing of the damping globally reduces the storey shear, on the other hand the interaction with the bracing stiffness increases the storey shear at some levels, mainly at the top levels, as already observed in the modal analysis. As a consequence, the frame storey shear is increased in the retrofit cases at the top levels with respect to the bare frame case, and the maximum increments are observed for the case combining the highest stiffness $K=1$ and the lowest damping $\xi_{a d d}=0.15$, and in the Stiff case.

Table 5 reports the shear actions resisted by the frame and by the tower, together with the total shear, for the five different configurations. It is noteworthy that the maximum shear for the tower and the frame do not necessarily occur at the same instant and the two values may have opposite signs, as already pointed out in the previous section. Thus, the value of the total shear may notably differ from the sum of the two contributions. In general, the base shear of the frame is reduced in all the retrofit scenarios with respect to the bare-frame case, and the base shear of the tower is lower than that of the frame. However, in some cases $\left(\kappa=1 ; \xi_{\text {add }}=0.30\right.$ and Stiff), the base shear resisted by the tower is very high and similar in value to the one of the frame. This may have an impact on the cost of the foundations of the tower.

The addition of the towers generally results in a reduction of the global shear demand at all the levels. A quite more complex behaviour can be observed for the shear forces in the frame, where two opposite contributions acts: on one hand, the increasing of the damping globally reduces the storey shear, on the other hand the interaction with the bracing stiffness increases the storey shear at some levels, mainly at the top levels, as already observed in the modal analysis. As a consequence, the frame storey shear is increased in the retrofit cases at the top levels with respect to the bare frame case, and the maximum increments are observed for the case combining the highest stiffness $K=1$ and the lowest damping $\xi_{\text {add }}=0.15$, and in the Stiff case.

Table 5. Shear actions results for the various configurations analysed

\begin{tabular}{|c|c|c|c|c|c|c|c|c|c|c|c|c|c|}
\hline \multirow[b]{2}{*}{ level } & \multirow{2}{*}{$\begin{array}{l}\text { Uncontrolled } \\
\qquad V_{i, \text { frame }} \\
{[\mathrm{kN}]}\end{array}$} & \multicolumn{3}{|c|}{$\kappa=0.5 ; \quad \xi_{\text {add }}=0.15$} & \multicolumn{3}{|c|}{$\kappa=1 ; \xi_{\text {add }}=0.15$} & \multicolumn{3}{|c|}{$\kappa=1 ; \xi_{\text {add }}=0.3$} & \multicolumn{3}{|c|}{ Stiff; $\xi_{\text {add }}=0.3$} \\
\hline & & $\begin{array}{c}V_{i \text {,frame }} \\
{[\mathrm{kN}]}\end{array}$ & $\begin{array}{c}V_{i, \text { tower }} \\
{[\mathrm{kN}]}\end{array}$ & $\begin{array}{l}V_{i, \text { total }} \\
{[\mathrm{kN}]}\end{array}$ & $\begin{array}{c}V_{i, \text { frame }} \\
{[\mathrm{kN}]}\end{array}$ & $\begin{array}{c}V_{i, \text { tower }} \\
{[\mathrm{kN}]}\end{array}$ & $\begin{array}{l}V_{i, \text { total }} \\
{[\mathrm{kN}]}\end{array}$ & $\begin{array}{c}V_{i, \text { frame }} \\
{[\mathrm{kN}]}\end{array}$ & $\begin{array}{c}V_{i, \text { tower }} \\
{[\mathrm{kN}]}\end{array}$ & $\begin{array}{l}V_{i, \text { total }} \\
{[\mathrm{kN}]}\end{array}$ & $\begin{array}{c}V_{i, \text { frame }} \\
{[\mathrm{kN}]}\end{array}$ & $\begin{array}{c}V_{i, \text { tower }} \\
{[\mathrm{kN}]}\end{array}$ & $\begin{array}{l}V_{i, \text { total }} \\
{[\mathrm{kN}]}\end{array}$ \\
\hline 1 & 25498 & 16796 & 8900 & 19970 & 17214 & 9379 & 19417 & 13129 & 12972 & 19547 & 13126 & 11008 & 15511 \\
\hline 2 & 22910 & 12523 & 6598 & 17750 & 11590 & 7156 & 16950 & 9237 & 9575 & 16882 & 7197 & 8846 & 13350 \\
\hline 3 & 20925 & 11206 & 5338 & 15907 & 10145 & 5994 & 15360 & 8292 & 7769 & 14944 & 6575 & 7505 & 11965 \\
\hline 4 & 19136 & 10954 & 3649 & 14012 & 9954 & 4284 & 13496 & 8346 & 5667 & 12866 & 6425 & 6261 & 10586 \\
\hline 5 & 16472 & 10165 & 2876 & 12219 & 9408 & 3556 & 11953 & 8105 & 4475 & 11700 & 6514 & 4703 & 8828 \\
\hline 6 & 12621 & 9154 & 2483 & 9960 & 8636 & 3406 & 9730 & 7614 & 3702 & 9688 & 6018 & 3513 & 6481 \\
\hline 7 & 7145 & 8177 & 3570 & 5948 & 8843 & 5096 & 5826 & 7707 & 4109 & 5898 & 8234 & 5869 & 3486 \\
\hline
\end{tabular}

Fig. 13 (a) reports the distribution of the shear actions along the height of the frame, normalized by dividing them by the value of the base shear in the Uncontrolled configuration. 
$\square$ Uncontrolled $\square_{\kappa=0.5 ;} \xi_{\text {add }}=0.15 \square_{\kappa=1 ;} \xi_{\text {add }}=0.15 \square_{\kappa=1 ;} \xi_{\text {add }}=0.3 \quad$ Stiff; $\xi_{\text {add }}=0.3$
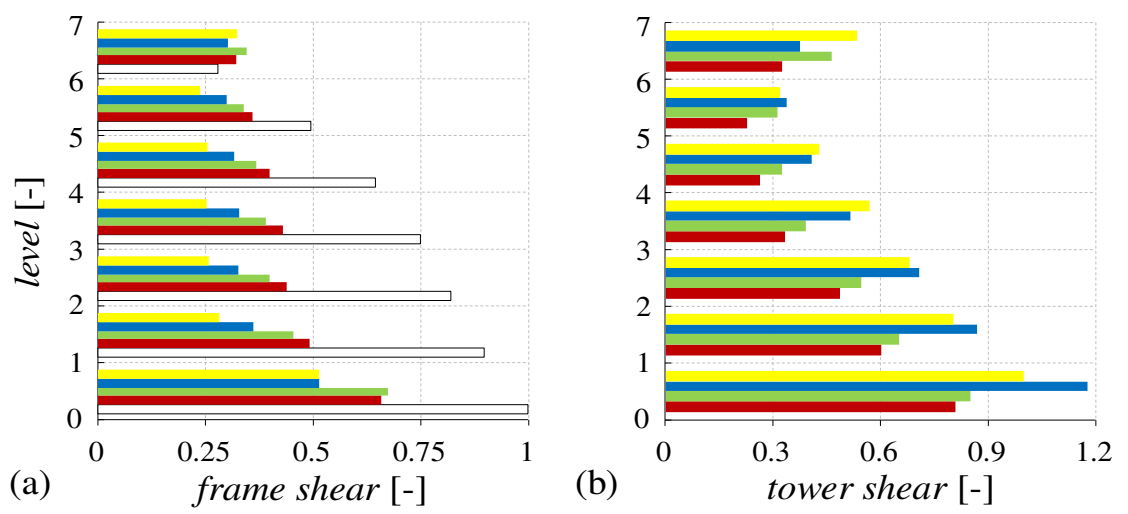

Fig. 13. Shear actions resisted by the frame (a) and by the tower (b) for the various configurations analysed

As observed for the displacements, similar performances are achieved for $\kappa=0.5 ; \xi_{\text {add }}=0.15$ and for $\kappa=1 ; \xi_{\text {add }}=0.15$. Fig. 13 (b) reports the distribution of the shear action in the tower along its height; the values are normalized by dividing them by the values of the base shear in the bracing for the case of infinitely stiff tower. From the analysis of Fig. 13 (a) and (b) it is observed that the configuration with $\kappa=1$ is a good approximation of the case of infinitely stiff tower, for the same given value of added damping ( $\xi_{\text {add }}=0.3$ ). It is also worth to point out that the shear demand at the top storey of the existing frame is increased for all the retrofit configurations analysed because of the mutual interaction with the external dissipative bracing system, while it is reduced at intermediate storeys.

The complex mode superposition approach is also employed to estimate the contribution of the higher modes of vibration on the shear actions before and after the retrofit. Table 6-7 report the distribution of the shear actions in the frame and the tower (Table 6) and of the global shear (Table 7) for the Uncontrolled case and for the different retrofit configurations, obtained by considering the contribution of the first mode only and of all the modes of vibration. Differently from the case of the displacements, the contribution of higher order modes is important as the values of both the frame and tower shear responses and the total shear response are significantly higher than the corresponding values obtained by considering the first mode only. Moreover, the contribution of the first mode to the total response of the frame increases due to the coupling with the dissipative tower, compared to the Uncontrolled configuration. In any case, the building response is dominated by the first mode of vibration also in the coupled case, especially for configurations with $K=1$.

Table 6. Higher order modes influence on the shear actions resisted by the frame and the tower

\begin{tabular}{|c|c|c|c|c|c|c|c|c|c|c|c|c|c|c|}
\hline \multirow[b]{2}{*}{ level } & \multicolumn{2}{|c|}{ Uncontrolled } & \multicolumn{4}{|c|}{$\kappa=0.5 ; \xi_{\text {add }}=0.15$} & \multicolumn{4}{|c|}{$\kappa=1 ; \xi_{\text {add }}=0.15$} & \multicolumn{4}{|c|}{$\kappa=1 ; \xi_{\text {add }}=0.3$} \\
\hline & $\begin{array}{c}V_{\text {full }} \\
{[\mathrm{kN}]}\end{array}$ & $\begin{array}{c}V_{1} \\
{[\mathrm{kN}]}\end{array}$ & $\begin{array}{c}V_{\text {frame_full }} \\
{[\mathrm{kN}]}\end{array}$ & $\begin{array}{l}V_{\text {framel }} \\
{[\mathrm{kN}]}\end{array}$ & $\begin{array}{c}V_{\text {tower_full }} \\
{[\mathrm{kN}]}\end{array}$ & $\begin{array}{l}V_{\text {tower1 }} \\
{[\mathrm{kN}]}\end{array}$ & $\begin{array}{c}V_{\text {frame_full }} \\
{[\mathrm{kN}]}\end{array}$ & $\begin{array}{c}V_{\text {framel }} \\
{[\mathrm{kN}]}\end{array}$ & $\begin{array}{c}V_{\text {tower_full }} \\
{[\mathrm{kN}]}\end{array}$ & $\begin{array}{l}V_{\text {tower1 }} \\
{[\mathrm{kN}]}\end{array}$ & $\begin{array}{c}V_{\text {frame_full }} \\
{[\mathrm{kN}]}\end{array}$ & $\begin{array}{l}V_{\text {framel }} \\
{[\mathrm{kN}]}\end{array}$ & $\begin{array}{c}V_{\text {tower_full }} \\
{[\mathrm{kN}]}\end{array}$ & $\begin{array}{l}V_{\text {tower1 }} \\
{[\mathrm{kN}]}\end{array}$ \\
\hline 1 & 25498 & 23620 & & 3 & & 9024 & 17214 & 172 & 9379 & & 13129 & 13 & 12972 & 16898 \\
\hline 2 & 22910 & 22340 & 12 & 49 & 6598 & 66 & 0 & 1 & 7156 & 0 & 7 & 099 & 9575 & 12594 \\
\hline 3 & 20925 & 20490 & & 39 & 5338 & & 45 & & 5994 & 5929 & 8292 & 8168 & 7769 & 10624 \\
\hline 4 & 19136 & 17722 & 10954 & 10642 & 3649 & 3734 & 9954 & 9745 & 4284 & 4094 & 8346 & 8297 & 5667 & 7817 \\
\hline 5 & 16472 & 14113 & 10165 & 9454 & 2876 & 2254 & 9408 & 8914 & 3556 & 2590 & 8105 & 7750 & 4475 & 5492 \\
\hline 6 & 12621 & 9815 & 9154 & 8042 & 2483 & 1291 & 8636 & 7922 & 3406 & 1730 & 7614 & 6944 & 3702 & 3202 \\
\hline 7 & 7145 & 5022 & 8177 & 7183 & 3570 & 3325 & 8843 & 8196 & 5096 & 4565 & 7707 & 7029 & 4109 & 3595 \\
\hline
\end{tabular}

Table 7. Higher order modes influence on the total shear actions

\begin{tabular}{|c|c|c|c|c|c|c|}
\hline \multirow[b]{2}{*}{ level } & \multicolumn{2}{|c|}{$\kappa=0.5 ; \xi_{\text {add }}=0.15$} & \multicolumn{2}{|c|}{$\kappa=1 ; \xi_{\text {add }}=0.15$} & \multicolumn{2}{|c|}{$\kappa=1 ; \xi_{\text {add }}=0.3$} \\
\hline & $\begin{array}{c}V_{\text {total_full }} \\
{[\mathrm{kN}]}\end{array}$ & $\begin{array}{l}V_{\text {total_1 }} \\
{[\mathrm{kN}]}\end{array}$ & $\begin{array}{c}V_{\text {total_full }} \\
{[\mathrm{kN}]}\end{array}$ & $\begin{array}{l}V_{\text {total_1 }} \\
{[\mathrm{kN}]}\end{array}$ & $\begin{array}{c}V_{\text {total_full }} \\
{[\mathrm{kN}]}\end{array}$ & $\begin{array}{l}V_{\text {total_1 }} \\
{[\mathrm{kN}]}\end{array}$ \\
\hline 1 & 19970 & 18130 & 19417 & 17259 & 19547 & 19160 \\
\hline 2 & 17750 & 17099 & 16950 & 16220 & 16882 & 18065 \\
\hline 3 & 15907 & 15688 & 15360 & 14845 & 14944 & 16591 \\
\hline 4 & 14012 & 13641 & 13496 & 12895 & 12866 & 14466 \\
\hline 5 & 12219 & 10977 & 11953 & 10388 & 11700 & 11691 \\
\hline 6 & 9960 & 7748 & 9730 & 7354 & 9688 & 8299 \\
\hline 7 & 5948 & 4033 & 5826 & 3843 & 5898 & 4346 \\
\hline
\end{tabular}


Table 8 reports the maximum values of the exchange forces $\left(F_{e, i}\right)$ observed at the various levels of the building, for the different retrofit configurations investigated; these actions are the result of the mutual actions between the tower and the existing building during the seismic event and they control the design of the connections between the tower and the frame. Fig. 14 shows the values of the exchange forces distribution, normalized by the value attained at the first floor for the Stiff case. The highest values of these exchange forces are observed at the first and at the last two floors for all the configurations and they are the result of the different signs of the shear action resisted by the frame and by the tower, as explained previously.

Table 8. Exchange forces results between frame and tower

\begin{tabular}{ccccc}
\hline \multirow{2}{*}{ level } & $\kappa=0.5 ; \xi_{\text {add }}=0.15$ & $\kappa=1 ; \xi_{\text {add }}=0.15$ & $\kappa=1 ; \xi_{\text {add }}=0.3$ & Stiff; $\xi_{\text {add }}=0.3$ \\
& $F_{e, i}[\mathrm{kN}]$ & $F_{e, i}[\mathrm{kN}]$ & $F_{e, i}[\mathrm{kN}]$ & $F_{e, i}[\mathrm{kN}]$ \\
\hline 1 & 5111 & 6312 & 5671 & 7042 \\
2 & 2658 & 2868 & 3328 & 2239 \\
3 & 2678 & 2989 & 3409 & 2115 \\
4 & 2034 & 2472 & 2723 & 2248 \\
5 & 2102 & 2427 & 2562 & 2017 \\
6 & 3196 & 4273 & 4039 & 5041 \\
7 & 3570 & 5096 & 4109 & 5869 \\
\hline
\end{tabular}

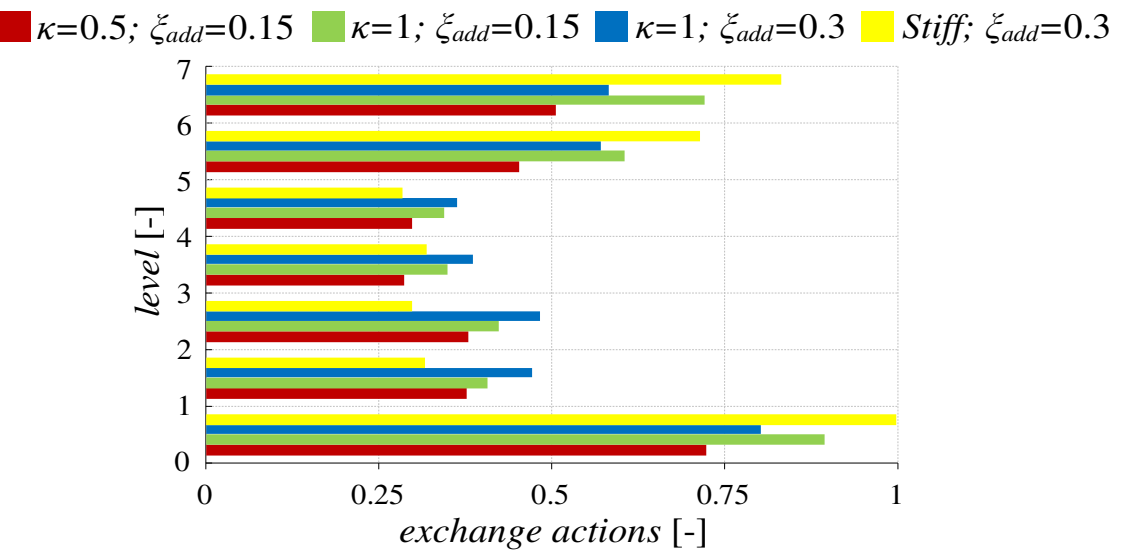

Fig. 14. Tower-frame exchange forces distribution along the height of the building for the various configurations analysed

Table 9 reports the values of the absolute acceleration observed at the various levels of the building for the configurations investigated. The coupling of the building with the external dissipative system induces a relative reduction of the maximum absolute acceleration values with respect to those observed in the Uncontrolled case. This result is of interest because the floor accelerations are significant for the performance evaluation of accelerationsensitive non-structural components, and often control the design of strategic buildings. Nevertheless, the reduction achieved for the acceleration is lower compared to that of the displacements, and this may impair the benefits of the retrofit. Fig. 15 shows the values of the floor absolute accelerations normalized by the value observed at the $7^{\text {th }}$ floor in the Uncontrolled case. The relative reduction of accelerations, measured at the last elevation, is nearly $49 \%$ for the Stiff configuration and about $17-19 \%$ for all the other cases involving a more realistic finite stiff tower (18\% for the $\kappa=1 ; \xi_{\text {add }}=0.3$ case, and $17 \%$ and $19 \%$, respectively, for the cases corresponding to $\kappa=0.5 ; \boldsymbol{\xi}_{\text {add }}=0.15$ and for $\left.\kappa=1 ; \xi_{\text {add }}=0.15\right)$. 
Table 9. Absolute accelerations for the various configurations analysed

\begin{tabular}{cccccc}
\hline level & $\begin{array}{c}\text { Uncontrolled } \\
\ddot{x}_{i}\left[\mathrm{~m} / \mathrm{s}^{2}\right]\end{array}$ & $\begin{array}{c}\kappa=0.5 ; \xi_{\text {add }}=0.15 \\
\ddot{x}_{i}\left[\mathrm{~m} / \mathrm{s}^{2}\right]\end{array}$ & $\begin{array}{c}\kappa=1 ; \xi_{\text {add }}=0.15 \\
\ddot{x}_{i}\left[\mathrm{~m} / \mathrm{s}^{2}\right]\end{array}$ & $\begin{array}{c}\kappa=1 ; \xi_{\text {add }}=0.3 \\
\ddot{x}_{i}\left[\mathrm{~m} / \mathrm{s}^{2}\right]\end{array}$ & $\begin{array}{c}\text { Stiff; } \xi_{\text {add }}=0.3 \\
\ddot{x}_{i}\left[\mathrm{~m} / \mathrm{s}^{2}\right]\end{array}$ \\
\hline 1 & 6.239 & 5.658 & 5.299 & 5.457 & 4.487 \\
2 & 7.742 & 6.795 & 6.109 & 6.443 & 3.959 \\
3 & 8.321 & 6.857 & 6.272 & 6.581 & 3.640 \\
4 & 8.286 & 6.523 & 6.161 & 6.356 & 3.642 \\
5 & 7.879 & 6.201 & 5.814 & 5.724 & 4.047 \\
6 & 9.336 & 6.829 & 6.609 & 6.536 & 4.950 \\
7 & 11.772 & 9.770 & 9.535 & 9.618 & 5.986 \\
\hline
\end{tabular}

$\square$ Uncontrolled $\square \kappa=0.5 ; \xi_{\text {add }}=0.15 \quad \kappa=1 ; \xi_{\text {add }}=0.15 \square \kappa=1 ; \xi_{\text {add }}=0.3 \quad$ Stiff; $\xi_{\text {add }}=0.3$

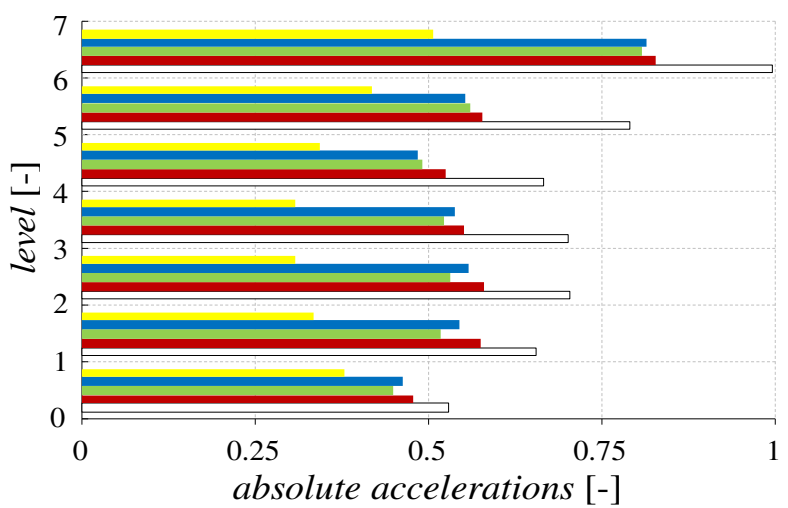

Fig. 15. Absolute acceleration distribution along the height for the various configurations analysed

Table 10 highlights the displacements $\left(y_{i}\right)$, velocities $\left(\dot{y}_{i}\right)$, axial forces $(N)$ and base viscous bending moment, related to damper axial actions $\left(M_{v}\right)$, for all the retrofit configurations considered. These quantities are strictly related to the added damping value. In fact, the Stiff and Retrofit configurations corresponding to $\xi_{\text {add }}=0.30$, give very similar results. It is noteworthy that also the case of $\kappa=0.5 ; \xi_{\text {add }}=0.15$, provides similar results, despite the lower added damping. Finally, the case of $\kappa=1 ; \xi_{\text {add }}=0.15$ provides the lowest value of the axial action on the FVDs, and thus also the lowest value of the viscous bending moment. This result is of interest in the design, since the bending moment transmitted by the tower controls the design of the tower's foundations. Normally, the foundation of the tower consists of drilled piles, which should be designed to support both the tension and compression forces induced by the rocking motion.

Table 10. Viscous dampers results

\begin{tabular}{|c|c|c|c|c|c|c|c|c|c|c|c|c|c|c|c|}
\hline \multicolumn{4}{|c|}{$\kappa=0.5 ; \xi_{\text {add }}=0.15$} & \multicolumn{4}{|c|}{$\kappa=1 ; \xi_{\text {add }}=0.15$} & \multicolumn{4}{|c|}{$\kappa=1 ; \xi_{\text {add }}=0.3$} & \multicolumn{4}{|c|}{ Stiff; $\xi_{\text {add }}=0.3$} \\
\hline $\begin{array}{c}y_{i} \\
{[\mathrm{~m}]}\end{array}$ & $\begin{array}{c}\dot{y}_{i} \\
{[\mathrm{~m} / \mathrm{s}]}\end{array}$ & $\begin{array}{c}N \\
{[\mathrm{kN}]}\end{array}$ & $M_{v}$ & $\begin{array}{c}y_{i} \\
{[\mathrm{~m}]}\end{array}$ & $\begin{array}{c}\dot{y}_{i} \\
{[\mathrm{~m} / \mathrm{s}]}\end{array}$ & $\begin{array}{c}N \\
{[\mathrm{kN}]}\end{array}$ & $M_{v}$ & $y_{i}$ & $\begin{array}{c}\dot{y}_{i} \\
{[\mathrm{~m} / \mathrm{s}]}\end{array}$ & $\begin{array}{c}N \\
{[\mathrm{kN}]}\end{array}$ & $M_{v}$ & $\begin{array}{c}y_{i} \\
\end{array}$ & $\begin{array}{c}\dot{y}_{i} \\
{[\mathrm{~m} / \mathrm{s}]}\end{array}$ & $\begin{array}{c}N \\
{[\mathrm{kN}]}\end{array}$ & $\begin{array}{c}M_{v} \\
{[\mathrm{kNm}]}\end{array}$ \\
\hline .0213 & .121 & 3773 & 33183 & .0216 & 0.127 & 1987 & 17482 & .0163 & 0.099 & 3101 & 27298 & .0158 & 0.102 & 3197 & 28131 \\
\hline
\end{tabular}

\section{CONCLUSIONS}

This paper investigates the seismic performance of existing buildings frames coupled with external dissipative towers consisting of a steel truss, hinged at the foundation level, whose rocking motion promotes the dissipation of energy by means of viscous dampers.

The system at hand is non-classically damped, being the energy dissipation concentrated at the tower base, and a suitable formulation is proposed for its analysis. In particular, a state-space approach and a complex modal analysis of the coupled system is proposed to evaluate the influence of the added tower stiffness and damping on both the dynamic and seismic behaviour, by highlighting the contribution of each of the complex vibration modes to the global seismic response. 
In order to evaluate benefits and drawbacks of the system, a parametric study is carried out, by considering several retrofit configurations which differ for the levels of added stiffness (tower-to-frame stiffness ratio $\kappa=1$ and $\kappa=0.5$ ) and dissipation capacity (damping ratio $\xi_{\text {add }}=0.15$ and $\xi_{\text {add }}=0.3$ ). The cases of the bare building (Uncontrolled) and of an infinitely stiff tower (Stiff), providing an added damping contribution of $30 \%$, are also considered for comparison purposes.

The results of the parametric analysis show in general that the addition of the towers leads to:

1 A regularization of the drift demand along the building height;

2 A reduction of the floor absolute accelerations, though to a less extent compared to the displacements;

3 The assumption of infinitely stiff dissipative tower, leading to simple closed form expression of the fundamental circular frequency and added damping, is quite accurate for all the retrofit cases considered;

4 The expression at the base of the proposed design procedure for the FVDs provides quite accurate results for all the retrofit cases considered in terms of added damping ratio, even if the system is highly non-classically damped;

5 The investigated retrofit configuration may lead to significant changes in the shear force distribution of the existing frame, as a consequence of the regularization of the interstorey drift demands, and this may reduce the benefits of the retrofit;

6 Higher order modes of vibration influence significantly the internal actions demand in the frame and the tower, while they do not significantly affect the displacement response;

7 The case corresponding to an infinitely stiff tower and 30\% added damping ratio provides the best distribution of absolute accelerations and inter-storey drifts. The retrofit configuration involving a tower with stiffness similar to that of the frame $(\kappa=1)$ and $30 \%$ added damping ratio provides results quite similar to those observed for the stiff tower case.

Future developments of the work should address the optimal design of the towers for irregular buildings, aiming at reducing the in-plane torsional behavior, and the geometrically and mechanically nonlinear structural response of the frame and of the tower, which is of interest for earthquakes with high intensity.

\section{AKNOWLEDGEMENTS}

The study reported in this paper was partially supported by the Italian Department of Civil Protection within the Reluis DPC Projects 2017. The authors gratefully acknowledge this financial support.

\section{REFERENCES}

[1] Soong TT, Dargush GF. Passive Energy Dissipation Systems in Structural Engineering. New York: Wiley; 1997.

[2] Soong TT, Spencer BF. Supplemental energy dissipation: state-of-the art and state-of-the practice. Engineering Structure 2002; 24: 243-259.

[3] Christopoulos C, Filiatrault A. Principles of Passive Supplemental Damping and Seismic Isolation. Pavia, Italy: IUSS Press, 2006.

[4] Ragni L, Dezi L, Dall'Asta A, Leoni G. HDR devices for the seismic protection of frame structures: Experimental results and numerical simulation. Earthquake Engineering and Structural Dynamics 2009; 38(10): 1199-1217. DOI:10.1002/eqe891

[5] Whittle JK, Williams MS, Karavasilis TL, Blakeborough A. Comparison of Viscous Damper Placement Methods for Improving Seismic Building Design. Journal of Earthquake Engineering 2012; 16(4): 540-560.

[6] Hwang JS, Lin WC, Wu NJ. Comparison of distribution methods for viscous damping coefficients to buildings. Structure and Infrastructure Engineering: Maintenance, Management, Life-Cycle Design and Performance 2013; 9(1): 28-41.

[7] Lavan O, Avishur M. Seismic behaviour of viscously damped yielding frames under structural and damping uncertainties. Bulletin of Earthquake Engineering 2013; 11(6): 2309-2332.

[8] Tubaldi E, Ragni L, Dall'Asta A. Probabilistic seismic response assessment of linear systems equipped with nonlinear viscous dampers. Earthquake Engineering and Structural Dynamics 2014; DOI: 10.1002/eqe.2462.

[9] Tubaldi E, Barbato M, Dall'Asta A. Efficient approach for the reliability-based design of linear damping devices for seismic protection of buildings. ASCE-ASME Journal of Risk and Uncertainty if Engineering Systems, Part A: Civil Engineering, special issue on Stochastic Dynamics and Reliability Analysis of Structural and Mechanical Systems Subject to Environmental Excitations 2015; DOI: 10.1061/AJRUA6.0000858.

[10] Dall'Asta A, Tubaldi E, Ragni L. Influence of the nonlinear behaviour of viscous dampers on the seismic demand hazard of building frames. Earthquake Engineering and Structural Dynamics 2016; 45(1): 149-169. 
[11] Dall'Asta A, Scozzese F, Ragni L, Tubaldi E. Effect of the damper property variability on the seismic reliability of linear systems equipped with viscous dampers. Bulletin of Earthquake Engineering 2017; 15: 5025-5053.

[12] Freddi F, Tubaldi E, Ragni L, Dall'Asta A. Probabilistic performance assessment of low-ductility reinforced concrete frames retrofitted with dissipative braces. Earthquake Engineering and Structural Dynamics 2012; 42(7): 993-1011.

[13] Özel AE, Güneyisi EM. Effects of eccentric steel bracing systems on seismic fragility curves of mid-rise R/C buildings: a case study. Structural Safety 2011; 33(1):82-95. DOI: 10.1016/j.strusafe.2010.09.001

[14] Kariniotakis K, Karavasilis T. Modified capacity design rule for columns in tall steel MRFs with linear viscous dampers within the framework of Eurocode 8. Bulletin of Earthquake Engineering 2018; 16: 917-932.

[15] Passoni C, Belleri A, Marini A, Riva P. Existing structures connected with dampers: state of the art and future developments. $2^{\text {nd }}$ European Conference on Earthquake Engineering and Seismology. Istanbul, Turkey, 25-29 August 2014.

[16] Trombetti T, Silvestri S. Novel Schemes for Inserting Seismic Dampers in Shear-Type Systems Based Upon the Mass Proportional Component of the Rayleigh Damping Matrix. Journal of Sounds and Vibrations 2007; 302: 486-526.

[17] Oren L, Abecassis D. Seismic behavior and design of wall-EDD-frame systems. Frontiers in Built Environment 2015. DOI: 10.3389/fbuil.2015.00007

[18] Impollonia N, Palmieri A. Seismic performance of buildings retrofitted with nonlinear viscous dampers and adjacent reaction towers. Earthquake Engineering and Structural Dynamics 2018; 1-23. https://doi.org/10.1002/eqe.3020

[19] Gattulli V, Potenza F, Lepidi M. Damping performance of two simple oscillators coupled by a dissipative connection. Journal of Sound and Vibration 2013; 332(26): 6934-6948.

[20] Tubaldi E, Barbato M, Dall'Asta A. Performance-based seismic risk assessment for buildings equipped with linear and nonlinear viscous dampers. Engineering Structures 2014: 78: 90-99.

[21] Tubaldi E. Dynamic behavior of adjacent buildings connected by linear viscous/visco-elastic dampers. Structural Control and Health Monitoring 2015; 22(8): 1086-1102.

[22] Tubaldi, E., Barbato, M., \& Dall'Asta, A. (2015). Efficient approach for the reliability-based design of linear damping devices for seismic protection of buildings. ASCE-ASME Journal of Risk and Uncertainty in Engineering Systems, Part A: Civil Engineering, 2(2), C4015009.

[23] Roia D, Gara F, Balducci A, Dezi L. Dynamic tests on an existing r.c. school building retrofitted with "dissipative towers". $11^{\text {th }}$ International Conference on Vibration Problems, Lisbon, Portugal, 9-12 September 2013.

[24] Roia D, Gara F, Balducci A, Dezi L. Ambient vibration tests on a reinforced concrete school building before and after retrofitting works with external steel" dissipative towers". Proceedings of the $9^{\text {th }}$ International Conference on Structural Dynamics, EURODYN 2014. Porto, Portugal, 30 June - 2 July 2014.

[25] Balducci A, Dissipative Towers. Application n. EP2010074723820100831, WO2010EP62748 20100831, International and European classification E04H9/02 - Italian concession n 0001395591, 2005.

[26] Gioiella L, Tubaldi E, Gara F, Dezi L, Dall'Asta A. Stochastic seismic analysis and comparison of alternative external dissipative systems. Journal of Shock and Vibration 2018. https://doi.org/10.1155/2018/5403737

[27] Alavi B, Krawinkler H. Strengthening of moment-resisting frame structures against near-fault ground motion effects. Earthquake Engineering and Structural Dynamics 2004; 33: 707-722. DOI: 10.1002/eqe.370.

[28] Ajrab JJ, Peckan G, Mander JB. Rocking wall-frame structures with supplemental tendon system. Journal of Structural Engineering 2004; 130(6): 895-203. DOI: 10.1061/(ASCE)0733-9445(2004)130:6(895).

[29] Marriott D, Pampanin S, Bull D, Palermo A. Dynamic testing of precast, post-tensioned rocking wall systems with alternative dissipating solutions. Bulletin of the New Zeland Society for Earthquake Engineering 2008; 41(2): 90-103.

[30] Qu Z, Wada A, Motoyui S, Sakata H, Kishiki S. Pin-supported walls for enhancing the seismic performance of building structures. Earthquake Engineering and Structural Dynamics 2012; 41: 2075-2091.

[31] Wu D, Lu X L. Structural performance evaluation of a new energy-dissipation and light-weight rocking frame by numerical analysis and experiment. Proceedings of the $10^{\text {th }}$ Pacific Conference on Earthquake Engineering Building and Earthquake-Resilient. Sidney, Australia, 6-8 November 2015. 
[32] Makris N, Aghagholizadeh M. The dynamics of an elastic structure coupled with a rocking wall. Earthquake Engineering and Structural Dynamics 2017; 46: 945-962.

[33] Aghagholizadeh M, Makris N. Seismic response of a yielding structure coupled with a rocking wall. Journal of Structural Engineering 2018; 144(2).

[34] MacRae G A, Kimura Y, Roeder C. Effect of column stiffness on braced frame seismic behavior. Journal of Structural Engineering 2004; 130(3).

[35] Blume J A \& Associates. Holiday Inn (Chapter 29, San Fernando Earthquake of February 9, 1971. Vol. I, Part A. U.S. Department of Commerce, National Oceanic and Atmospheric Administration: Washington, DC, 1973.

[36] Islam M S. Analysis of the Northridge earthquake response of a damaged non-ductile concrete frame building. The Structural Design of Tall Buildings 1996; 5: 151-182.

[37] Trifunac M D, Ivanovic S S, Todorovska M I. Apparent periods of a building. I: Fourier Analysis. Journal of Structural Engineering 2001; 127(5): 517-526.

[38] Porter K A, Beck J L, Shaikhutdinov R V. Investigation of sensitivity of building loss estimates to major uncertain variables for the Van Nuys testbed. PEER Report 2002/03, College of Engineering, University of California, Berkeley August 2002.

[39] Krawinkler H. Van Nuys Hotel building testbed report: exercising seismic performance assessment. PEER Report 2005/11, Department of Civil and Environmental Engineering, Stanford University, October 2005.

[40] Meyer C editors. Modeling and Analysis of Reinforced Concrete Structures for Dynamic Loading. CISM Courses and Lectures No. 346, Springer Wien, 1998.

[41] Kim J, Choi H, Min K W. Performance-based design of added viscous dampers using capacity spectrum method. Journal of Earthquake Engineering 2003; 7(1): 1-24.

[42] ASCE Standard ASCE/SEI 41-13: Seismic Evaluation and Retrofit of Existing Buildings. American Society of Civil Engineers, 2014.

[43] MATLAB, The MathWorks Inc., 1994.

[44] EN 1993 Eurocode 3 - Design of steel structures.

[45] Somerville P, Smith N, Punyamurthula S, Sun J. Development of Ground Motion Time Histories for Phase II of the FEMA/SAC Steel Project. SAC Background Document Report, Report No. SAC/BD-97/04, 1997.

[46] Claret A M, and Venancio-Filho F. A modal superposition pseudo-force method for dynamic analysis of structural systems with non-proportional damping. Earthquake Engineering and Structural Dynamics 1991; 20(4): 303-315

[47] SEAOC, Vision 2000: Performance Based Seismic Engineering of Buildings. Structural Engineers Association of California, San Francisco, April 1995. 